CENTRE FOR COMPARATIVE ECONOMICS

E\&BUP

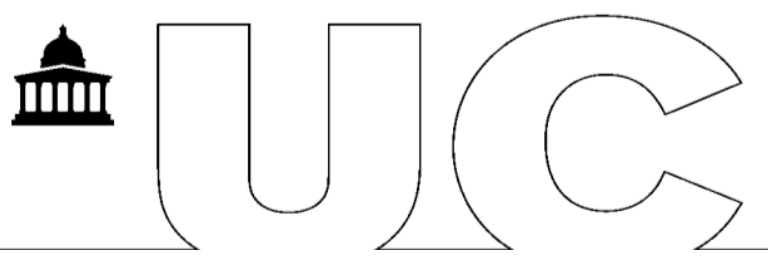

UCL SSEES

Centre for Comparative Economics

\title{
Assessing the Impact of the Maternity Capital Policy in Russia Using a Dynamic Model of Fertility and Employment
}

\author{
Fabián Slonimczyk ${ }^{a}$ \\ Anna Yurkoa \\ ${ }^{a}$ International College of Economics and Finance. NRU Higher School of Economics, Moscow, Russia \\ Economics and Business Working Paper No.125 \\ November 2013
}

Centre for Comparative Economics UCL School of Slavonic and East European Studies

Gower Street, London, WC1E 6BT

Tel: +44 (0)20 76798519

Fax: +44 (0)20 76798777 


\title{
Assessing the Impact of the Maternity Capital Policy in Russia Using a Dynamic Model of Fertility and Employment*
}

\author{
Fabián Slonimczyk ${ }^{\dagger \sharp} \quad$ Anna Yurko ${ }^{\dagger}$
}

November 15, 2013

\begin{abstract}
With declining population and fertility rates below replacement levels, Russia is currently facing a demographic crisis. Starting in 2007, the federal government has pursued an ambitious pro-natalist policy. Women who give birth to at least two children are entitled to "maternity capital" assistance $(\$ 11,000)$. In this paper we estimate a structural dynamic programming model of fertility and labor force participation in order to evaluate the effectiveness of the policy. We find that the program increased long-run fertility by about 0.15 children per woman.
\end{abstract}

JEL classification: J13, C61

Key words: fertility; female labor supply; structural estimation; Russia

${ }^{*}$ This paper has been presented at the following venues: IZA-HSE workshop, Royal Economic Society, Atlanta Federal Reserve Bank, Society of Labor Economics, Eastern Economic Association, Asia Meetings of the Econometric Society, European Economic Association, European Labor Economics Association, Lancaster University, University College London. We are grateful to participants for helpful comments and suggestions. In addition, we thank Irina Denisova, Vladimir Gimpelson, Hartmut Lehmann, Sergey Roshin, and Judith Shapiro for useful comments. All remaining errors are our own. Anna Yurko acknowledges support from the Center of Advanced Studies at NRU Higher School of Economics (individual research grant).

${ }^{\dagger}$ International College of Economics and Finance. NRU Higher School of Economics, Moscow, Russia; ${ }^{\sharp}$ IZA, Bonn, Germany; fslonimczyk@hse.ru and ayurko@hse.ru. 


\section{Introduction}

For several decades now, economists have theorized fertility decisions as a special case of consumers' utility maximization problem. ${ }^{1}$ Children produce certain satisfactions and have a net cost, and couples have to decide on the optimal number of children. A more recent development involves the recourse by a number of governments to the use of direct financial incentives in an attempt to revert declining fertility rates. While the details are different in each case, Australia, France, Germany, Canada (the province of Quebec), and Spain have all offered "baby bonuses" to couples.

Russia is among the countries with very low fertility rates: its total fertility rate (TFR) over the period 2001-2005 was only $1.3 .^{2}$ In order to encourage women to have more children, the State Duma (Russian Parliament) passed a law in December of 2006 establishing new measures of government support for families with children, commonly known as the maternity capital (MC) program. According to the law, starting in January 2007 women that give birth to or adopt a second or consecutive child are entitled to special financial assistance. The program is scheduled to expire by the end of $2016 .^{3}$

$\mathrm{MC}$ assistance comes in the form of a certificate that entitles its holder to receive funds in the amount of approximately $\$ 11,000$ at any time after the child reaches the age of three. ${ }^{4}$ The money can be used for a limited number of purposes. Specifically, parents can receive these funds if they intend to spend them on: 1) acquiring housing, 2) paying for children education, or 3) investing in the mother's retirement fund. Women can apply for MC funds only once in their lifetimes.

Through the end of 2012, the Russian government has issued over four million MC certificates. ${ }^{5}$ At the approximate value of $\$ 11,000$ per certificate, total liabilities due to the MC program are growing at a rate above $\$ 7$ billion per annum, or $2.1 \%$ of total federal government expenditures in 2012. In comparison, the fraction of the federal budget dedicated to education was $4.8 \%$. Fortunately for public finances, parents are in no rush to claim and spend the money: out of the issued certificates only $37.4 \%$ have been claimed

\footnotetext{
${ }^{1}$ See Becker (1960) for an early formulation. Hotz et al. (1997) and Arroyo and Zhang (1997) review the literature.

${ }^{2}$ The TFR is defined as the total number of children born to the average woman over her lifetime. It is computed as the sum of the current age-specific fertility rates. Population size is steady when the TFR is around 2.1. For an overview of recent demographic trends in Russia, see Denisova and Shapiro (2013) and Brainerd (2012).

${ }^{3}$ Currently, there is discussion over whether to extend the program until the end of 2025 .

${ }^{4}$ The amount in Russian rubles is revised annually to adjust for inflation. See table A.1 in the appendix.

${ }^{5}$ Source: Pension Fund of the Russian Federation. Annual Report 2012.
} 
so far (23.9\% fully claimed), most of them (over 90\%) used on acquiring and improving housing conditions.

How effective is this policy in increasing fertility? In 2006, Gary Becker wrote in his blog on the expected effect of the proposed MC policy: "I would guess that Russian fertility would increase by about 10-20 percent from current levels, or from the present total fertility rate of 1.28 to perhaps as high as 1.55." Four years into the program Russia's TFR was 1.58. It seems that Becker's prediction has been correct and the policy results in more births.

Predictably, the government attributes the higher birth rates to its policies, specifically to the MC program. Russian demographers are more skeptical, however, noting that the TFR has been increasing since 2000 at approximately constant rates and that TFR and other aggregate measures of fertility are very unreliable indicators of actual fertility behavior (Zakharov, 2012).

There are some previous studies that investigate the effect of financial incentives on fertility. For example, Dickert-Conlin and Chandra (1999) estimate that increasing the tax benefit of having a child by $\$ 500$ raises the probability of having the child in the last week of December by 26.9 percent. Similarly, using three substantial changes in tax policy in France, Chen (2011) finds mixed evidence that fertility responds to positive and negative changes in tax incentives. Gans and Leigh (2009) find that in Australia over 1000 births were "moved" so as to ensure that their parents were eligible for the Baby Bonus, with about one quarter being moved by more than one week. Finally, Milligan (2005) finds that the introduction of a pronatalist transfer policy in the Canadian province of Quebec had a strong effect on fertility.

Assessing the effect of the MC policy is challenging for two main reasons. First, there is the classic issue of confounding factors. In particular, the Russian government made changes to maternity leave and child benefits around the same time the MC policy was introduced. A second challenge is that the fertility decisions of the women affected by the program will only be fully observable after they complete their fertile period. Without further assumptions it is not possible to distinguish an increase in completed fertility from a shift in the timing of births.

In order to investigate whether the MC program has been successful in increasing fertility rates while addressing these challenges, in this paper we estimate a dynamic stochastic discrete choice model of fertility and employment. We then use the estimates of the structural parameters to analyze the effect of the policy. The model we estimate builds on previous dynamic fertility models such as Wolpin (1984), Francesconi (2002) and Keane and Wolpin (2007), and explicitly accounts for the differential costs and benefits 
of first vis a vis consecutive births. We also let the utility associated with births to differ in the post-reform period to control for changes in maternity leave and child benefits. Finally, because women in the model are forward looking and rational, we are able to distinguish increases in long run fertility from shifts in the timing of births.

Based on model simulations, we find that the MC policy has very modest long-run effects on fertility (about 0.15 children per woman). As expected, the main effect on fertility has been to increase the fraction of women who choose to have two or more children. The model confirms that a significant fraction of observed increases in fertility rates right after the reform was implemented are due to short-run rescheduling of births rather than actual increases in long-run fertility. The MC policy has had heterogeneous effects. Specifically, we find that the increases in birth rates are larger among women without a college degree and women who are married or cohabiting with a spouse. There are no significant differences between rural and urban areas or by employment status.

The paper is structured as follows. The next section provides a detailed discussion of the methodological challenges associated with evaluating the MC policy and our strategy to overcome them. Section three presents diverse descriptive evidence on the effectiveness of the policy, including results from a 2008 poll, data on aggregate fertility rates from different sources, and results for before-after and difference-in-differences experiments. This descriptive evidence provides a benchmark against which we assess the estimates based on the structural model. Section four describes the model and the estimation method. Section five provides details on the estimating sample. Section six presents estimation results and evaluates the ability of the model to fit the data. In section seven we present simulation-based estimates of the short- and long-run effects of the MC program. Section eight concludes.

\section{Evaluating the MC Policy: Methodological Chal- lenges}

This section provides details regarding the changes to fertility-related policies in Russia. It then discusses the methodological challenges associated with evaluating the effect of the MC policy on fertility and our proposed strategy to overcome them. 


\subsection{The Maternity Capital Program}

Maternity capital is a federal program that became effective in January 2007 and is set to expire by the end of $2016 .{ }^{6}$ Women that give birth to or adopt a second or consecutive child are entitled to special financial assistance. This assistance comes in the form of a certificate that entitles its holder to receive a certain amount of funds. The amount - on average about 11,000 dollars - is indexed annually to compensate for inflation. The last column of table A.1 presents the MC benefit amount since the program was implemented. Women can apply to receive the certificate at any point after giving birth to an eligible child, but only once in their lifetimes. In case of the mother's death the certificate passes to the father, and if he dies as well - to the child him- or herself.

According to the original design, the family could use the funds only after the eligible child reaches the age of three and only for one (or a combination) of three purposes: 1) purchasing housing; 2) children education; and 3) investment in mother's pension fund. ${ }^{7}$ The funds are transferred directly from the Pension Fund - the administrator of the program - to the seller of the property, the mortgage holder, the educational institution, or the mother's pension fund account, depending on the purpose.

\subsection{Other Fertility-related Policies in Russia}

There is a set of overlapping fertility-related policies in Russia, many of which have been revised in the period under study. First, employed women are eligible for a total of 140 days of maternity leave (split equally before and after delivery). ${ }^{8}$ Maternity leave is fully compensated up to a maximum amount that is updated yearly. As shown in table A.1, starting in 2005 maximum benefits have increased continuously in value.

In addition to regular maternity leave, employed women can opt for extended paid leave until the child is 1.5 years of age. ${ }^{9}$ Before 2007 these benefits consisted of a low fixed amount. A substantial reform introduced

\footnotetext{
${ }^{6}$ The statute that created the policy is entitled "Of the Additional Measures of Support for Families with Children", number N 256-FZ from December 29th 2006.

${ }^{7}$ Several changes have been made since the law was first enacted. First, beginning in January 2009 the funds can be used for mortgage payments immediately after the birth of the eligible child (i.e. without the three year waiting period). Second, since August 2010 the funds can also be used for construction of housing. In this case the money is either transferred directly to the construction company or to the certificate holder if she is doing the construction herself and after the proper paperwork is submitted to the Pension Fund. Finally, from 2009 to the end of the first quarter of 2011, maternity capital certificate holders were allowed to withdraw 12,000 rubles in cash.

${ }^{8}$ The source is federal law $81-\mathrm{FZ}$ "Of the state benefits for citizens with children" $(19 / 05 / 1995)$ and its subsequent amendments. Multiple pregnancies and births with complications are entitled to additional 30 days of leave.

${ }^{9}$ Maternity leave can be further extended until the child is 3 years old. However, the
} 
several changes starting January 2007. Benefits became a fixed proportion (40\%) of the mother's salary. However, a floor and a ceiling for benefits were also introduced. Columns 3-5 of table A.1 present the extended maternity leave minimum and maximum benefits over the period. The reform set minimum benefits that differ by birth order. These amounts are relatively low and only a small minority of women with a regular job have earnings that fall in the range where the birth order distinction is relevant.

The 2007 reform also introduced for the first time a maternity allowance for non-employed women. ${ }^{10}$ These benefits are set at the same level as the minimum payment to employed women in extended maternity leave. Overall, the reform of maternity benefits offered additional incentives for women to have children. For non-employed and a minority of very low-paid women, benefits became larger for higher order births.

\subsection{Methodological Strategy}

Assessing the effect of the MC policy is challenging for two main reasons. First, evaluation faces the usual challenge of confounding factors. Changes in other economic and non-economic determinants could explain any observed increases in fertility behavior around the time the MC program was introduced. In particular, as we have seen, the Russian government made changes to maternity leave and child benefits around the same time. Because in principle these policies are of universal application it is not easy to delineate reliable treatment-control distinctions that would allow identifying the effect of the MC policy on fertility.

One possibility is to exploit the fact that the the MC program targets second and consecutive births while other policies target all birth orders to obtain a difference-in-differences (DID) estimate of the effect of the reform. However, this strategy has several problems. First, some minor aspects of the changes to child benefits are in fact a function of birth order. Specifically, after 2007 the minimum benefit paid to employed women in extended maternity leave and all non-employed mothers is larger for second and consecutive children than for first borns. Second, even after controlling for a large number of observable characteristics, it is not possible to rule out the fact that the decision to give birth to a first child is fundamentally different from the decision to have two or more children. In particular, arguably the former decision is less sensitive to monetary incentives than the latter, so a change in economic conditions around the time the policy was introduced or the changes made to other fertility-related policies could bias the DID

monthly benefits after the 18th month are negligible (50 rubles) and have not changed over time.

${ }^{10}$ All women who give birth are eligible to a one-time payment in cash. Column 6 of table A.1 presents the amounts. 
estimate.

The second challenge to evaluation is that the fertility decisions of the women affected by the MC program will only be fully observable after they complete their fertile period. Without further assumptions it is not possible to distinguish an increase in completed fertility from a shift in the timing of births. Such re-scheduling could be important if women discount the future heavily and/or suspect the benefits might become unavailable at a later date. ${ }^{11}$

For these reasons, before-after or difference-in-differences estimates are likely to be biased upwards. In order to correct for these biases we explicitly model the fertility decision in a dynamic stochastic setting. This strategy has several advantages. First, by considering the dynamic aspects of the decision, the model is able to distinguish short-run rescheduling of births from long-run changes in overall fertility. Second, the model explicitly accounts for the differential costs and benefits of first vis a vis consecutive births and allows the utility associated with births to shift in response to changes in maternity leave and child benefits. Third, considering fertility and labor supply simultaneously allows incorporating the MC policy explicitly through the budget constraint. Including potential earnings in the model provides a scale against which women assess the value of the MC benefit. We are also able to obtain selection-adjusted estimates of the effect of the policy on employed and non-employed women. This last point is important because the birth-order-dependent aspects of the changes to child benefits are much more significant for the latter group. Thus, the model also provides a robustness check against the confounding effect of these policies. ${ }^{12}$

These advantages come at a cost. Specifically, as is the case with any modeling exercise, we need to make functional form and distributional assumptions. Section four below presents the model and discusses the assumptions one by one. We further discuss the limitations of our modelling strategy in the concluding section.

\section{Descriptive Evidence}

This section presents diverse descriptive evidence on the effect of the MC program on fertility. After introducing the data sources, we present time

\footnotetext{
${ }^{11} \mathrm{~A}$ different kind of rescheduling - women delaying births until right after the policy is in place - is unlikely to be an issue in this case. The policy changes were introduced in the State Duma late in 2006 and became effective almost immediately. According to poll results, two years after the MC program was in place one in three women and half the men were completely uninformed about the existence of the policy (see table A.2 in the appendix).

${ }^{12}$ Note, however, that we cannot completely rule out that a fraction of the estimated effect of the MC program comes from these other birth-order-dependent policies.
} 
series evidence on birth rates and the total fertility rate based on official registry data. Next, we use individual data from a representative sample to obtain before-after and differences-in-differences estimates using both regression and matching techniques. As argued above, we expect these estimates to be biased upwards. The rationale for presenting them is twofold. First, these estimates provide an upper bound to the effect of the MC policy on fertility. Second, they offer a natural metric against which to assess the estimates obtained from the structural model. We conclude the section by presenting results from a poll on the effects of the MC program.

\subsection{Data Sources}

Official aggregate data on birth rates and total fertility rates is available from the Russian statistical agency's (Rosstat) website for the years 20002011. Information on earlier years comes from the Human Fertility Database (HFD). ${ }^{13}$ These data are collected from official registries, so it is the best existing source on fertility behavior in Russia. However, it is only available at aggregate level and does not provide any information other than the mother's age and birth order.

The main data source for this study is the Russian Longitudinal Monitoring Survey (RLMS), a household panel survey based on the first national probability sample drawn in the Russian Federation. ${ }^{14}$ In a typical round, 10,000 individuals in 4,000 households are interviewed. These individuals reside in 32 oblast (regions) and 7 federal districts of the Russian Federation. A series of questions about the household (the "family questionnaire") are answered by one household member selected as the reference person. In turn, each adult in the household is interviewed individually (the "adult questionnaire"), providing information on labor market participation, experience, schooling and earnings.

We use the family roster to create a fertility history for each woman in the panel. Specifically, we record a birth every time a new child appears in the household roster. For households interviewed for the first time, we record a birth if the child is less than one year old. Because interviews are conducted between October and December, fertility measures using the RLMS do not exactly correspond to a calendar year. Below (figures 1 and 2) we compare fertility measures using the RLMS and official sources. As can be expected from a representative sample, the RLMS data is noisier but follows the official statistics quite closely.

\footnotetext{
${ }^{13}$ The Human Fertility Database. Max Planck Institute for Demographic Research and Vienna Institute of Demography. Available at www.humanfertility.org.

${ }^{14}$ The RLMS is conducted by the Higher School of Economics and the "Demoscope" team in Russia, together with Carolina Population Center, University of North Carolina at Chapel Hill.
} 
Figure 1 - Birth Rates for Women Ages 15-49

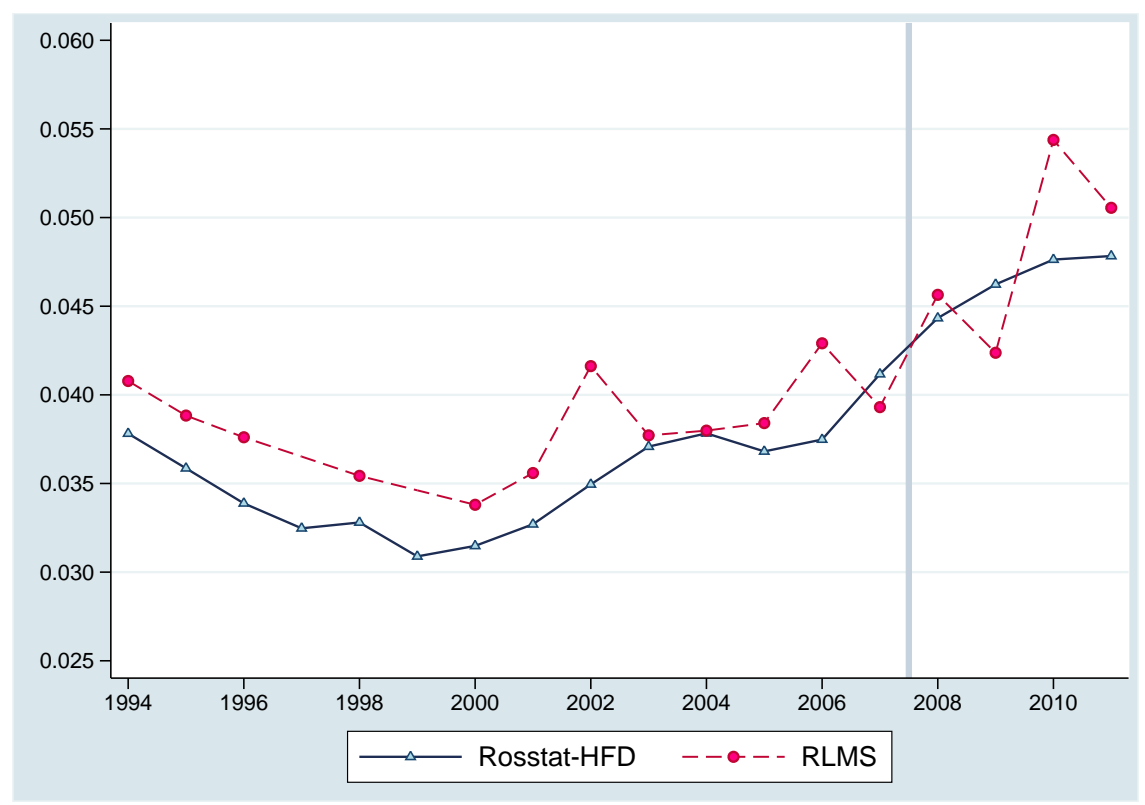

Notes: The data for the Rosstat-HFD series is from the Human Fertility Database for 1994-1999 and from Rosstat for 2000-2011.

\subsection{Aggregate Trends}

Figure 1 shows official statistics on birth rates (BR) for women ages 15 to 49. The Rosstat-HFD series shows a declining trend during the late 90s. After a quick bounce back in the early 2000s, births per woman stabilized around a level of $3.7 \%$ in the years before the MC program was introduced. Starting in 2007, the BR has increased steadily and reached the highest level in the period under analysis. ${ }^{15}$

The BR is highly sensitive to changes in the age composition of the female population. An alternative indicator of overall fertility is the total fertility rate (TFR), which is the sum of the age-specific birth rates at a point in time. The TFR is independent of relative cohort sizes and measures fertility in an easy to interpret metric (number of children per woman). Its main shortcoming is that it implicitly extrapolates the fertility behavior of older cohorts and applies it to younger cohorts. According to the official statistics, the TFR in Russia followed a path similar to the birth rate (see figure 2), so the increase in fertility does not seem to be an artifact of the age composition of the population.

\footnotetext{
${ }^{15}$ Note, however, that this maximum is still a low point in historical perspective (see figure A.1 in the appendix).
} 
Figure 2 - Total Fertility Rate

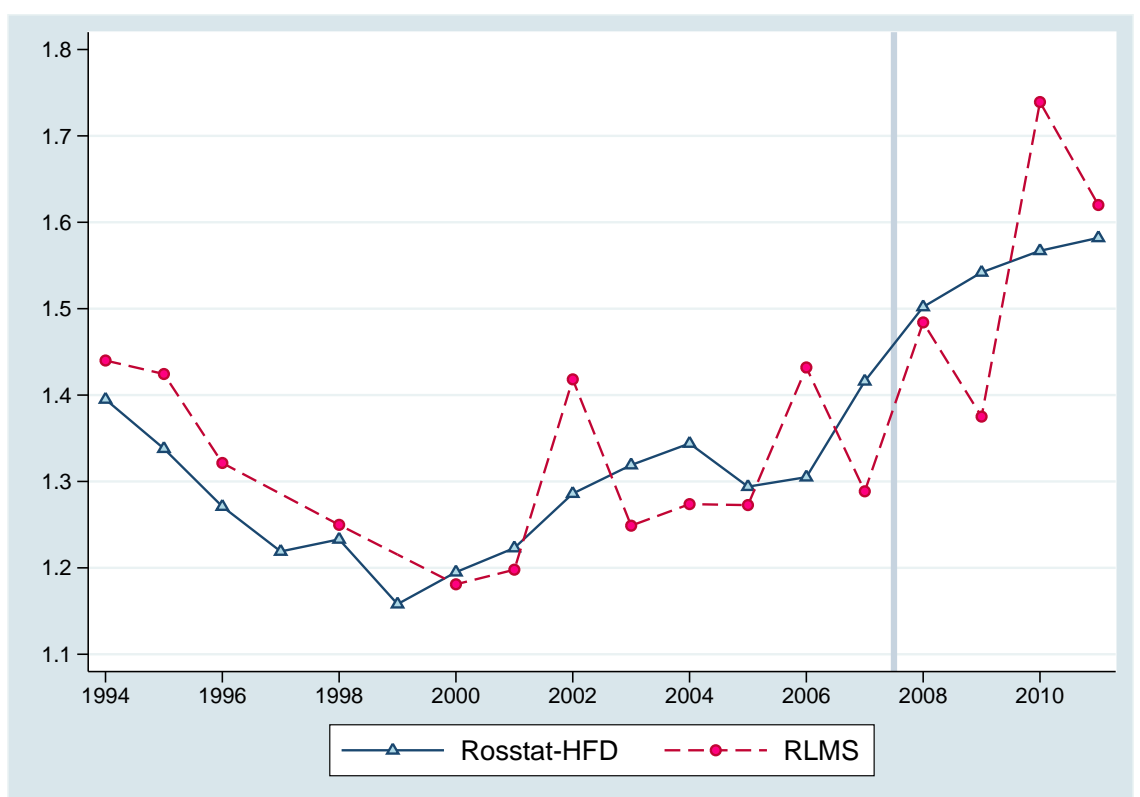

Notes: The data source is the same as in figure 1. The TFR is the sum of all age-specific fertility rates at a point in time.

Figure 3 - Birth Rates By Birth Order for Women Ages 15-49

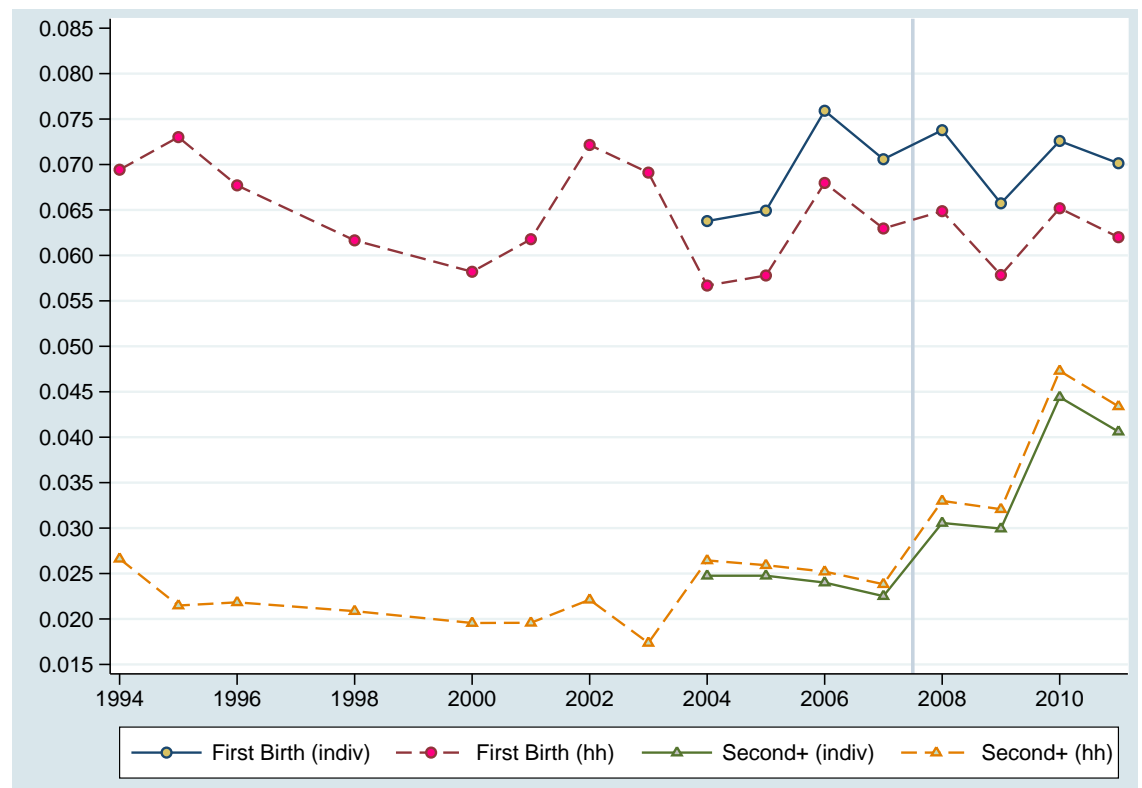

Notes: The data source is the RLMS. The series based on the individual questionnaire (indiv) use an item asking for the number of children the respondent has. The series based on the family questionnaire (hh) use the number of sons and daughters living in the household. "Second+" refers to second and consecutive birth orders. 
Figure 3 shows birth rates by birth order using the RLMS data. ${ }^{16}$ An item in the adult questionnaire that asks for the number of children the person has can be used to determine birth order but is only available starting in 2004. The family questionnaire provides information on the number of sons and daughters for all years on the condition that they live in the household. The discrepancy between the two series is caused by births by relatively older women with children outside the household. ${ }^{17}$

Regardless of which source is used to determine birth order, it is clear that the rate of first births was fairly constant over the period and that the increase in the birth rate in recent years is due exclusively to second and consecutive births. Since the MC policy explicitly targeted women with at least one child, the evidence on birth rates of different orders can in principle be counted as in favor of a positive effect of the program on fertility.

\subsection{Before-After and Difference-in-Differences Estimates}

It is possible to use the individual level data from the RLMS to obtain more formal tests of the hypothesis that the MC policy increased fertility, while also controlling for a number of observable characteristics. Specifically, we estimate the following equations:

$$
\begin{aligned}
\text { birth }_{i t}= & \alpha_{0}+\alpha_{1} \text { post }_{t}+f_{1}\left(\text { age }_{i t}\right)+\boldsymbol{X} \gamma_{\mathbf{1}}+\varepsilon_{1} \\
\text { birth }_{i t}= & \beta_{0}+\beta_{1} \text { post }_{t}+\beta_{2} \text { MCelig }{ }_{i t}+\beta_{3}(\text { MCelig } \\
& +f_{2}\left(\text { age }_{i t}\right)+\boldsymbol{X} \boldsymbol{\gamma}_{\mathbf{2}}+\varepsilon_{2}
\end{aligned}
$$

where birth is an indicator of whether woman $i$ gave birth in period $t$ and post is an indicator equal to one for the years 2008-2011 and zero otherwise. Note that while the policy was put in place in January 2007, a large majority of the births observed in that year's RLMS interview correspond to pregnancies from 2006. ${ }^{18}$ The variable MCelig equals one for women with one or more children and who have not given birth to a second or consecutive child after 2007. Correspondingly, it is zero in two cases: 1) for women without children, and 2) for women with two or more children after the birth of a second or consecutive child in the program period. ${ }^{19}$

\footnotetext{
${ }^{16}$ Birth rates by birth order are also available from the HFD. They closely follow the RLMS series and are omitted to keep the figure uncluttered.

${ }^{17}$ Figure A.2 in the appendix shows the same series restricted to younger women.

${ }^{18}$ Using the child's month of birth, we constructed a quarterly birth rate series (available upon request from authors). We found no evidence of an increase in births of any order in the last quarter of 2007 (in fact, the birth rate in that quarter is substantially lower than in quarters $1-3)$.

${ }^{19}$ Since we do not have information on program take-up, the best we can do is look at the effect of eligibility. This is equivalent to intent-to-treat analysis in clinical trials.
} 
We estimate equation (1) for MC-eligible women only. Under the strong assumption that no other important unobservable determinant of fertility changed at the same time as the MC policy was implemented, the beforeafter (BA) comparison summarized by the $\alpha_{1}$ parameter identifies the effect of the program.

An alternative strategy is to apply difference-in-differences (DID). The $\beta_{3}$ parameter in equation (2) identifies the causal effect under the well-known "common trends" assumption, namely that any time-varying unobservables have the same effect on treated and non-treated women. ${ }^{20}$ Note that this estimate is a lower-bound since the MC program could also incentivize first births by increasing the option-value of a second birth later on.

Columns numbered 1 through 7 in table 1 present OLS estimates of the treatment effects for different specifications of the age function $(f(\cdot))$ and the set of control variables $(\boldsymbol{X}) .{ }^{21}$ Standard errors are robust and clustered at the individual level, as recommended by Bertrand et al. (2004).

The BA and DID estimates are very similar and robust to the inclusion of a wide variety of controls. We have applied special care to controlling for age of the mother, which is obviously an important factor determining fertility behavior. We experimented with a quadratic functional form, as well as with the inclusion of age-group dummies, and a linear and a cubic spline. We have also included marital status, a number of demographic and human capital characteristics, household composition, and year and location dummies. ${ }^{22}$ Finally, in some specifications we included controls for the age of the youngest child, as well as a series of indicators for the availability and cost of child care in the locality where the woman lives.

The estimated effect on the birth probability always falls in the range 1.6-2.4\%, which is consistent with figure 3 . We can obtain a back-of-theenvelope estimate of the expected increase in the number of children as follows.

\footnotetext{
${ }^{20}$ This is only approximately equivalent to the assumption that unobservables affect first births and higher birth orders equally since our treatment indicator also depends on whether the woman gave birth after the program was in place.

${ }^{21}$ Table A.3 in the appendix presents the full regression results for specification 7 . Other estimation results are available from the authors.

${ }^{22}$ Table 1 contains the full list of control variables.
} 


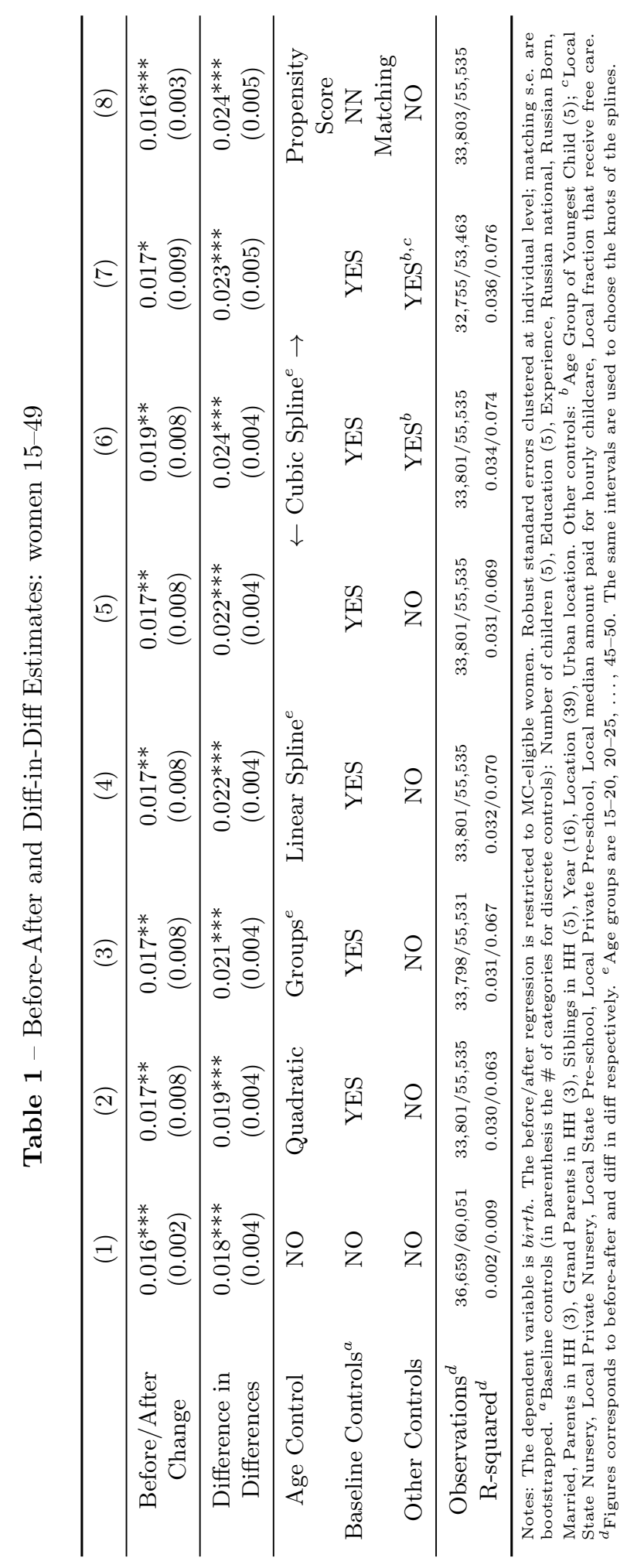


The life period we analyze is 34 years long (15 to 49 year olds). Our estimates indicate that the average treated woman's birth probability increased by approximately $2 \%$ per annum. This gives an expected increase of $0.02 \times 34 \approx 0.68$ children over the life period considered. Since in the post-reform period roughly $58 \%$ of women were treated, the implication is that the program led to an estimated overall increase in fertility of about 0.4 children. This is consistent with the increase in TFR shown in figure 2 .

In sum, these estimates tell us that the increase in birth rates observed after 2007 is not an artifact of changes in age composition or in any of the other observable determinants of fertility in the control set. It also confirms that the increase in second and consecutive births is statistically significant.

As a final robustness check, we obtained BA and DID estimates based on a nearest-neighbor matching technique. Specifically, we calculated

$$
\begin{aligned}
\widehat{B A}_{\text {match }}= & \frac{1}{n_{T \cap P}} \sum_{i \in T \cap P}\left[\text { birth }_{i}-\text { birth }_{T \cap \bar{P}}^{n n(i)}\right] \\
\widehat{D I D}_{\text {match }}= & \frac{1}{n_{T \cap P}} \sum_{i \in T \cap P}\left[\text { birth }_{i}-\operatorname{birth}_{\bar{T} \cap P}^{n n(i)}\right] \\
& -\frac{1}{n_{T \cap \bar{P}}} \sum_{i \in T \cap \bar{P}}\left[\text { birth }_{i}-\operatorname{birth}_{\bar{T} \cap \bar{P}}^{n n(i)}\right]
\end{aligned}
$$

where $T$ is the set of MC-eligible women, $P$ is the set of women observed in the program years, and $n_{x}$ is the number of individuals in set $x$. The BA matching estimator in equation (3) compares births by MC-eligible women post 2007 with their matched counterparts in the pre 2008 period (the set $T \cap \bar{P})$. The match is chosen by the nearest neighbor criterion applied to the propensity score metric. ${ }^{23}$ Matching is done without replacement and ties are resolved by randomization. We impose the common support condition. ${ }^{24}$ The propensity score is estimated via a logit model with post as the dependent variable and age plus all the baseline controls in the righthand-side (see table 1 for a list; year dummies are excluded).

The DID estimator in equation (4) is based on double matching (see Smith and Todd, 2005). MC-eligible women before and after the program was effective are matched to ineligible women. The matching criterion is again nearest neighbor. The propensity score is estimated on the $P$ and $\bar{P}$ sub-samples by logit models with MC-eligibility as the dependent variable and age and all baseline controls (including year) in the right-hand-side.

Matching-based estimates are presented in the last column of table 1. These estimates are statistically undistinguishable from the ones obtained

\footnotetext{
${ }^{23}$ We experimented with other matching techniques and obtained similar results.

${ }^{24}$ The region of common support is the subset of values of the controls that are observed in both groups under comparison.
} 
Table 2 - Result of Poll on MC Policy

\begin{tabular}{|c|c|c|}
\hline & Males & Females \\
\hline MC influenced the \# of children they want & $\begin{array}{c}2.8 \% \\
(3,821)\end{array}$ & $\begin{array}{c}4.2 \% \\
(3,755)\end{array}$ \\
\hline $\begin{array}{l}\text { Average \# of Children Desired } \\
\ldots \text { if claims not to have been influenced }\end{array}$ & $\begin{array}{c}1.6 \\
(3,516)\end{array}$ & $\begin{array}{c}1.6 \\
(3,472)\end{array}$ \\
\hline ... if claims to have been influenced & $\begin{array}{c}1.9 \\
(102)\end{array}$ & $\begin{array}{l}1.8 \\
(147)\end{array}$ \\
\hline $\begin{array}{l}\text { MC influenced decision to } \mathrm{to}^{\ddagger} \ldots \\
\ldots \text { give birth/get pregnant/adopt }\end{array}$ & - & $\begin{array}{l}5.6 \% \\
(339)\end{array}$ \\
\hline$\ldots$ give birth and desired \# of children & - & $\begin{array}{l}3.0 \% \\
(303)\end{array}$ \\
\hline ... give birth but not the desired \# of children & - & $\begin{array}{l}3.3 \% \\
(303)\end{array}$ \\
\hline
\end{tabular}

via regression. The OLS estimator imposes a restrictive linear-additive form to the control function. In addition, OLS does not restrict estimation to the region of common support, so an unknown level of extrapolation goes undetected. Given that the matching estimates are very close to the regression estimates, we can rule out that the findings in this sub-section are due to the specifics of OLS regression. However, it should be emphasized that matching is no silver bullet. In particular, the identification assumptions behind the BA and DID strategies are fundamentally the same in all cases.

\subsection{Discussion}

In this section we have presented diverse evidence on the effectiveness of the MC policy. First, aggregate time series evidence based on registry data shows a significant increase both in the BR and in the TFR. The increase in births is explained exclusively by second and higher birth orders. Second, BA and DID estimates show that the increase in fertility is not due to changes in any of a large number of control variables. A researcher giving these estimates a causal interpretation would conclude that the MC policy increased total fertility by about 0.4 children per woman.

However, as argued above, the identification assumptions of BA and DID estimates are unlikely to hold in this case. Specifically, improvements in maternity leave and child benefits are probably responsible for part of the increase in birth rates. In addition, previous studies (eg. Dickert-Conlin and Chandra, 1999, Gans and Leigh, 2009) suggest that the rescheduling of births is a common response to pronatalist policies. Both of these factors imply that the BA and DID estimates are biased upwards.

The 2008 round of the RLMS included a series of questions on the MC policy that were administered as part of the adult questionnaire. The results, presented in table 2, provide further evidence suggesting that the effect of the 
$\mathrm{MC}$ is likely to be more modest than suggested by reduced form estimates. ${ }^{25}$ Only about $3 \%$ of males and $4 \%$ of females claimed that MC had led them to reconsider the number of children they would like to have. The difference in the number of desired children between those who claimed to have been influenced and those who claimed not to have been influenced is 0.2 among women and 0.3 among men. The questionnaire also included a number of items that were asked to women who qualify for a MC certificate (i.e. women who had given birth to or adopted a second or consecutive child since January 2007). Of these women, only $5.6 \%$ answered that the MC program had influenced their decision to have one more child.

The remaining poll questions try to separate the effect on birth timing vis a vis real increases in lifetime fertility. The responses imply that in about half the cases the program only influenced the chosen timing of the birth and not the total number of desired children.

\section{The Model}

This section presents a dynamic stochastic model of fertility and labor force participation. We consider a woman making decisions among discrete alternatives at each point in time so as to maximize the present value of expected lifetime utility. The model focuses on two decisions. First, at each age $t$ the woman decides whether to participate in the job market $\left(l_{t}=1\right) \cdot{ }^{26}$ Second, women in fertile age can choose to give birth $\left(n_{t}=1\right)$. To simplify matters, we assume fertility is a deterministic process over which women have full control. ${ }^{27}$ We index the four mutually exclusive alternatives facing women by $j$ :

$$
j= \begin{cases}1 & \text { if no birth and no work } \\ 2 & \text { if no birth and work } \\ 3 & \text { if birth and no work } \\ 4 & \text { if birth and work }\end{cases}
$$

We let the decision process start at age 22, set the end of the fertile

\footnotetext{
${ }^{25}$ Table A.2 in the appendix presents additional poll results regarding knowledge of the program and preferred use of MC benefits.

${ }^{26}$ Part-time work is relatively rare in Russia. Only $3.3 \%$ of employed women in our sample work 20 or less hours per week. For this reason, we do not allow for separate fulland part-time participation decisions. We emphasize that from here on $t$ stands for the woman's age, and not calendar time.

${ }^{27}$ Other studies, such as Hotz and Miller (1988), specify complex stochastic functions that make the probability of a birth depend on, among other factors, birth control intensity and the age of the mother. In our model, the utility of births has a random component. These two modeling strategies are not separately identifiable.
} 
period at age 45 , and end the program at the official retirement age of $55 .{ }^{28}$ The starting point is convenient since a vast majority of Russian women finish their education by age $22 .{ }^{29}$ Moreover, while some women become mothers at a younger age, second births - the focus of the MC policyoccur after our starting age in over $99 \%$ of cases. Formally, the woman's objective function can be written

$$
\mathrm{E}\left[\sum_{t=22}^{54} \rho^{t-22} U_{t}\left(c_{t}, l_{t}, l_{t-1}, n_{t}, n_{t-1}, n_{t-2}, X_{t-1}, N_{t}, B_{t}, S, m_{t}, \mathbb{I}_{\text {post }}\right)\right]
$$

where $\rho$ is the subjective rate of discount and the expectation is taken over the stochastic components of utility and earnings. ${ }^{30}$ Women derive utility from consumption of a composite good $\left(c_{t}\right)$, giving birth, and (disutility) from working. Utility is not intertemporally separable since labor market experience $\left(X_{t-1}\right)$, the total number of children $\left(N_{t}\right)$, the age of the youngest child $\left(B_{t}\right)$, as well as lagged employment and births - all of them results from past decisions - are assumed to affect current tastes. Utility is also affected by the woman's education $(S)$ and marital status $\left(m_{t}\right)$. While education remains constant over time, marital status is assumed to evolve following a first-order markovian process whose underlying parameters are allowed to change as the woman ages. ${ }^{31}$ Finally, $\mathbb{I}_{\text {post }}$ is an indicator equal to one in the period post 2007 and zero otherwise. ${ }^{32}$ The specific functional form for the utility function is

$$
\begin{aligned}
U_{t}= & c_{t}+\alpha_{1} l_{t}+\left(\alpha_{2}+\epsilon_{t}^{n}\right) n_{t}+\alpha_{3} \mathbb{I}_{N_{t}=1}+\alpha_{4} \mathbb{I}_{N_{t}=2}+\alpha_{5} \mathbb{I}_{N_{t}>2} \\
& +\beta_{1} c_{t} l_{t}+n_{t}\left[\beta_{2} c_{t}+\beta_{3} l_{t}+\beta_{4} l_{t-1}+\beta_{5} n_{t-1}+\beta_{6} n_{t-2}\right. \\
& +\mathbb{I}_{N_{t}>1}\left(\beta_{7}+\beta_{8} \epsilon_{t}^{n}+\beta_{9} l_{t-1}\right) \\
& +\beta_{10} \mathbb{I}_{t<\underline{A}}+\beta_{11} \mathbb{I}_{t>\bar{A}}+m_{t}\left(\beta_{12} \mathbb{I}_{t<\underline{A}}+\beta_{13} \mathbb{I}_{t>\bar{A}}\right) \\
& \left.+\mathbb{I}_{\text {post }}\left(v_{0}+v_{1} l_{t-1}+v_{2} l_{t-1} \mathbb{I}_{N_{t}>1}\right)\right] \\
& +m_{t}\left[\delta_{1} l_{t}+\delta_{2} n_{t}+\delta_{3} I_{N_{t}=1}+\delta_{4} I_{N_{t}=2}+\delta_{5} I_{N_{t}>2}\right]
\end{aligned}
$$

\footnotetext{
${ }^{28}$ The estimation process ignores any fertility decision after the cutoff age. The last decision period is $t=54$.

${ }^{29}$ According to the RLMS, only $0.5 \%$ of women 22 and older are students.

${ }^{30}$ Technically, the expectations operator should be age subscripted because the starting marital status affects future outcomes.

${ }^{31}$ Specifically, we estimate outside the model transition matrices for women in different age intervals (see table A.4 in the appendix for the transition probabilities). We experimented with a version of the model that allowed for parental cohabitation as a second random state and disaggregated non-labor income coming from the spouse and from other household members. The extra complication neither substantially improved the model fit nor changed the key results.

${ }^{32}$ Throughout the paper, $\mathbb{I}_{x}$ is an indicator equal to the truth value of $x$.
} 


$$
\begin{aligned}
& +l_{t}\left[\gamma_{1} X_{t-1}+\gamma_{2} S_{1}+\gamma_{3} S_{2}+\gamma_{4} S_{3}+\gamma_{5} S_{4}\right. \\
& \left.+\gamma_{6} I_{N_{t}=1}+\gamma_{7} I_{N_{t}=2}+\gamma_{8} I_{N_{t}>2}+\gamma_{9} I_{B_{t} \leq 3}\right]
\end{aligned}
$$

Instantaneous utility is linear and additive in consumption. Giving birth has both a deterministic $\left(\alpha_{2}\right)$ and a stochastic $\left(\epsilon_{t}^{n}\right)$ effect on utility. Work and births affect the marginal utility of consumption and births affect the marginal disutility of work. To better fit the data on the timing of births, we also include interactions with previous recent births, second or consecutive birth order, work in the previous period, and with a step function in the age of the woman. ${ }^{33}$

As discussed above, there were changes in maternity leave and child benefit policies post-2007. In addition, there might have been changes in the social environment that we would like to control for. For this reason, utility parameters $(v)$ associated with giving birth are allowed to change in the post-reform period. Specifically, we let the new maternity leave and child benefit policies to shift the utility of giving birth, as well as the interaction of birth and work at the time of pregnancy. Since the minimum extended maternity leave payment varies by birth order, we also include an interaction term for becoming pregnant with a second or higher order child.

Marital status does not enter utility directly but modifies the effect of births, employment, and children. The disutility of work depends on previous work experience (habit formation), highest education completed ${ }^{34}$, and the number of children. Finally, we let the work interactions to depend on the presence of a small child (3 years old or less). ${ }^{35}$

The model does not permit either savings or borrowing. Consumption each period must equal total income minus the costs associated with work, giving birth, and rearing children. Formally, the budget constraint is written:

$$
\begin{aligned}
c_{t}= & y_{t}^{f} l_{t}+y_{t}^{o}+\phi M C n_{t} K \\
& -b_{1} l_{t}-b_{2} n_{t}-b_{3} I_{N_{t}=1}-b_{4} I_{N_{t}=2}-b_{5} I_{N_{t}>2}
\end{aligned}
$$

The linearity in consumption of the utility function means that the parameters corresponding to these monetary costs $\left(b_{s}\right)$ cannot be separately identified from the "psychic" benefits. Therefore, we set the former parameters to zero and interpret the latter as benefits net of cost.

\footnotetext{
${ }^{33} l_{t-1}$ approximates work at the time when the pregnancy occurred. After some experimentation, we found that setting $\underline{A}=25$ and $\bar{A}=35$ gave the best fit.

${ }^{34} S_{1}$ through $S_{4}$ correspond to secondary school, vocational school, technical school, and university respectively.

${ }^{35}$ In Russia, women can take extended maternity leave until the child turns three. In addition, typically children start kinder garden at the same age.
} 
Women receive labor income $y_{t}^{f}$ when employed and income from other household members $y_{t}^{o}$. In addition, eligible women $(M C=1)$ receive maternity capital assistance in the amount $K$ if they give birth. ${ }^{36}$ Because assistance can only be obtained three years after the birth and must be used for specific purposes, we estimate a parameter $(\phi)$ that converts assistance dollars into a monetary equivalent consumption value. ${ }^{37}$ The $\phi$ parameter is separately identified from $v_{2}$ because MC eligibility does not depend on employment and can be claimed only once in the lifetime.

The woman's income from other household members depends on her characteristics. Women are assumed to form expectations according to

$$
\overline{\log y_{t}^{o}}=d_{0}+d_{1} m_{t}+d_{2} t+d_{3} t^{2}+d_{4} S_{1}+d_{5} S_{2}+d_{6} S_{3}+d_{7} S_{4}+d_{8} G
$$

where $G$ indicates urban residence. Equation (7) does not depend on current or future decisions so it is estimated outside the model. ${ }^{38}$ Note that nonlabor income depends on the random state $\left(m_{t}\right)$, so women use the transition probabilities in table A.4 to estimate the expected value.

Women receive a job offer with a probability $\left(\pi_{t}\right)$ that depends on whether they were employed the previous period and whether they reside in an urban area. Formally,

$$
\begin{aligned}
\pi_{t} & =\frac{\exp \left(\psi_{t}\right)}{1+\exp \left(\psi_{t}\right)} \\
\psi_{t} & =z_{0}+z_{1} l_{t-1}+z_{2} G
\end{aligned}
$$

The earnings offer function depends on the woman's accumulated human capital as follows:

$$
\log y_{t}^{f}=a_{0}+a_{1} X_{t-1}+a_{2} X_{t-1}^{2}+a_{3} S_{1}+a_{4} S_{2}+a_{5} S_{3}+a_{6} S_{4}+a_{7} G+\epsilon_{t}^{y}
$$

The shock $\epsilon_{t}^{y}$ captures variation in earnings that is independent of the decision process. ${ }^{39}$ The two shocks $\left(\epsilon_{t}^{n}, \epsilon_{t}^{y}\right)$ are jointly normally distributed with zero mean, finite variance, and non-zero contemporaneous covariance.

\footnotetext{
${ }^{36}$ We set $K$ equal to the average real value (in rubles of year 2011) of MC assistance over the period 2007-2011. See table A.1 in the appendix.

${ }^{37}$ Keane and Wolpin (2010) use the same procedure when evaluating welfare participation in the U.S.

${ }^{38}$ See table A.5 in the appendix for the estimated coefficients.

${ }^{39}$ Table A.5 presents OLS estimates of the earnings regression and logit estimates of the employment probability. We use these coefficients as starting values in the ML search.
} 
The shocks are assumed to be serially independent, so past realizations do not provide information on future shocks.

The model allows for unobserved individual heterogeneity in the following parameters: disutility of work $\left(\alpha_{1}\right)$, utility of giving birth $\left(\alpha_{2}\right)$, utility associated with having children $\left(\alpha_{3}-\alpha_{5}\right)$, the baseline job offer probability $\left(z_{0}\right)$, the baseline earnings $\left(a_{0}\right)$, and the MC multiplier $(\phi)$. Heterogeneity is introduced as a set of unobservable types, with each type having its own associated set of parameters. ${ }^{40}$ The proportion of women corresponding to each type is estimated jointly with the model parameters as explained below.

In addition to the shocks and the realization of the marital status process, the state variables informing employment and fertility decisions include the history of choices up to age $t$. Let the state space be denoted by $\Omega_{t}{ }^{41}$. The value function $V\left(\Omega_{t}\right)$ is the maximal expected present value of the remaining lifetime utility given the state at age $t .{ }^{42}$ Because the alternatives facing the woman are discrete, the value function can be written as the maximum over alternative-specific value functions:

$$
V\left(\Omega_{t}\right)=\max _{j \in J_{t}}\left[V_{j}\left(\Omega_{t}\right)\right]
$$

where $J_{t}=\{1, \ldots, 4\}$ for $t=22, \ldots, 45$ and $J_{t}=\{1,2\}$ for $t=46, \ldots, 54$. The alternative-specific value functions obey the Bellman equation:

$$
\begin{aligned}
V_{j}\left(\Omega_{t}\right) & =U_{j, t}+\rho \mathrm{E}_{t}\left[V\left(\Omega_{t+1}\right) \mid \Omega_{t}, j \in J_{t}\right] & & \text { for } t<54 \\
& =U_{j, 54} & & \text { for } t=54
\end{aligned}
$$

Finally, the pre-determined state variables evolve according to

$$
\begin{aligned}
N_{t} & =N_{t-1}+n_{t} \\
X_{t-1} & =X_{t-2}+l_{t-1} \\
B_{t} & = \begin{cases}1 & \text { if } n_{t-1}=1 \\
B_{t-1}+1 & \text { otherwise }\end{cases}
\end{aligned}
$$

\footnotetext{
${ }^{40}$ We experimented allowing heterogeneity in other parameters (e.g. $\left.\delta_{2}-\delta_{5}, \sigma^{n}\right)$ but the resulting estimates were very close to each other.

${ }^{41} \Omega_{t}=\left(l_{t-1}, N_{t-1}, X_{t-1}, n_{t-1}, n_{t-2}, B_{t}, S_{1}, \ldots, S_{4}, G, \overline{y_{t}^{o}}, m_{t}, \mathbb{I}_{\text {post }}, M C, \epsilon_{t}^{n}, \epsilon_{t}^{y}\right)$

${ }^{42}$ Technically, because this is a finite horizon problem, the value function should be age-subscripted. We omit it to simplify notation (the subscript would always be the same as that of the state space).
} 


\subsection{Model Solution and Estimation}

The solution to the finite-horizon dynamic programming problem can be found using backward recursion, which in turn enters into the estimation of the structural parameters.

A woman in her last period only needs to evaluate two alternatives. The alternative utility levels depend on the pre-determined part of the state space $\left(\Omega_{t}^{d}\right)$ and the particular realization of the random components. ${ }^{43}$ Therefore, the last period's decision can be seen as a static random utility model. Given data on actual decisions of 54 year old women, their earnings, and the observable components of the state space, it would be straightforward to obtain parameter estimates using maximum likelihood methods.

The extension to a dynamic setting is better understood by first considering 53 year old women. While still facing two alternatives, women of this age need to consider the effect of their choices on the next period's prospects. For example, evaluating the alternative "work" involves the following steps: 1) compute the flow utility corresponding to the alternative "work" at age $53 ; 2$ ) Update the state space for age 54 (e.g. add one year of experience); 3) Given the new state, the fact that she will act optimally at age 54 allows the use of the value functions for age 54 (this is the recursive step); 4) With these inputs it is possible to calculate the age 53 value of working.

These steps need to be repeated for the alternative "not work". At this point, the decision at age 53 only depends on the (unobservable to the researcher) shock $\epsilon_{t}^{y}{ }^{44}$ Given data for 53 year old women, the solution to the dynamic program makes it possible to estimate the parameter values that maximize the likelihood of observed behavior. The same logic applies to younger women. ${ }^{45}$

Letting $d_{i, t}$ denote the combination of the choice and earnings (i.e. $d_{i, t}=$ $j$ for $j=1,3$ and $d_{i, t}=\left(j, y_{t}^{f}\right)$ for $\left.j=2,4\right)$ for woman $i$ at age $t$, we have

$$
\begin{array}{rlrl}
\operatorname{Pr}\left(d_{i, t} \mid \Omega_{t}^{d}\right)= & \operatorname{Pr}\left(j=\arg \max _{k} V_{k}\left(\Omega_{t}\right)\right) & & \text { for } j=1,3 \\
\operatorname{Pr}\left(d_{i, t} \mid \Omega_{t}^{d}\right)= & \operatorname{Pr}\left(j=\arg \max _{k} V_{k}\left(\Omega_{t}\right)\right) & \\
& \times \operatorname{Pr}\left(y_{t}^{f} \mid j=\arg \max _{k} V_{k}\left(\Omega_{t}\right)\right) & \text { for } j=2,4
\end{array}
$$

Given the serial independence of the shocks, the joint probability of a sequence of choices is

\footnotetext{
${ }^{43}$ Marital status is included in $\Omega_{t}^{d}$.

${ }^{44}$ Only women in fertile age are affected by $\epsilon_{t}^{n}$.

${ }^{45}$ The solution for women 45 years old and younger is more computationally demanding since it involves the doubling of the decision tree that must be considered.
} 


$$
\operatorname{Pr}\left(d_{i, 22}, \ldots, d_{i, 54} \mid \Omega_{22}^{d}\right)=\prod_{t=22}^{54} \operatorname{Pr}\left(d_{i, t} \mid \Omega_{t}^{d}\right)
$$

In turn, the likelihood for a sample of women is simply the product of (10) over the $N$ women in the sample. In order to generate the probabilities in the right hand side of (10), we solve the dynamic program for 30 simulations of the random shocks and use a kernel smoothing function (McFadden, 1989). Thus, the estimation program involves two loops: the first loop iterates over parameter values, while the second loop - for given parameter values - solves the model using backward recursion and obtains via simulation the likelihood of observing the actual choices in the data. The procedure stops when the likelihood of the sample data is maximized.

The introduction of unobservable types into the model modifies the objective likelihood function as follows

$$
\mathrm{L}_{i}(\boldsymbol{\theta})=\sum_{h=1}^{H} \kappa_{h} \prod_{t=22}^{54} \operatorname{Pr}\left(d_{i, t} \mid \Omega_{t}^{d}, \text { type }=h\right)
$$

where $\boldsymbol{\theta}$ is the vector of parameters, including the errors variance-covariance matrix and the type proportions $\left(\kappa_{h}\right){ }^{46}$

It is standard in this setting to assume earnings are measured with error. Let observed earnings, $\widetilde{y}_{t}^{f}$, be given by

$$
\begin{aligned}
\log \widetilde{y}_{t}^{f} & =\log y_{t}^{f}+u_{t}^{f} \\
u_{t}^{f} & \sim \mathrm{N}\left(0, \sigma_{u}^{2}\right)
\end{aligned}
$$

where $u_{t}^{f}$ is measurement error, which is assumed to be uncorrelated with other shocks and also over time. The rationale for including measurement error in the estimation step is twofold. First, it is reasonable to believe that earnings are not reported accurately. Second, an extra error component is necessary to prevent a degenerate likelihood due to outliers. Technically, this could happen in situations when the woman is observed working but her earnings are too low to justify her decision given the parameter values and the realized earnings shock. ${ }^{47}$

\footnotetext{
${ }^{46}$ The only non-estimated parameter is the time discounting rate, $\rho$, which we set to 0.95 .

${ }^{47}$ Alternatively, one could include a random disturbance to the disutility of work. However, it would be harder to justify the assumption of zero correlation, both with other shocks and serially.
} 


\section{$5 \quad$ Estimating Sample}

In this section we provide details on how we processed the RLMS data in order to estimate the structural model.

\subsection{Variable Definitions}

Employment The RLMS contains information on a main job and a secondary job. ${ }^{48}$ A woman is considered employed if she usually works 10 or more hours per week at all jobs.

Experience The adult questionnaire includes an item regarding past labor market experience. We construct our experience variable as follows. First, we use the RLMS data to determine previous experience in the first round the individual is interviewed. ${ }^{49}$ In subsequent rounds we let experience evolve in a way that is consistent with the observed employment history.

Births and number of children As already mentioned, whether a woman has given birth during the year preceding interview is determined on the basis of the household roster. The procedure to create our number of children variable is analogous to the one applied for labor market experience. First, we use an item from the adult questionnaire to determine the number of children in the first round the woman is observed. We then let the variable evolve in a manner consistent with her birth history.

Marital Status We consider a woman as married when there is a cohabiting spouse in the household roster. While information on marital status is also available from the individual questionnaire, the emphasis on cohabitation better represents the opportunity set confronting the woman.

Labor and Other Income The RLMS contains information on the previous month's after-tax earnings for each job, as well as an item on overall after-tax income. Our labor income variable adds earnings from the main and the second job. Individuals who work less than 10 hours per week are imputed zero labor income. Women receive other income from three sources: a) income in excess of labor income, b) income from the spouse or partner, and c) some fraction of income from other household members.

\footnotetext{
${ }^{48}$ In addition, there are a series of items regarding irregular informal activities. We do not consider irregular activities in determining employment status.

${ }^{49} \mathrm{In}$ cases when the response is missing, we use data from other rounds to impute a value.
} 
The first source is calculated as the difference between total after-tax income and our labor income variable. The second is obtained from the spouse's answer to the RLMS individual questionnaire. In order to estimate the third component, we proceed as follows. From the household interview, we obtain total after-tax family income. From this amount we subtract the woman's income and (if present) the spouse's income. Finally, we assume that the woman receives a fraction of this income that is proportional to the size of her nuclear family (herself, her spouse, and children living in the household) relative to overall household size. All nominal amounts are converted to rubles from year 2011 using the Russian CPI.

\subsection{Sample Selection and Descriptive Statistics}

Our sample is composed of women between 22 and 54 years of age. The model requires accurate information on the number of children each woman has regardless of her age. These data are available for the years 2004-2011. After deleting observations with missing values in the relevant variables, our unbalanced panel comprises 9,462 individuals and a total of 32,934 personyear observations. Table 3 has descriptive statistics.

In our model, women's fertile period ends exogenously at age 45 . Over $74 \%$ of individuals enter our sample before crossing this threshold. Women in the sample exhibit wide variation in initial labor market experience and education attainment.

Women in our sample have completed fertility rates significantly below the replacement rate. For example women over 40 have on average 1.72 children. Low fertility rates occur despite the fact that Russia has one of the highest marriage rates in the world.

Table 4 focuses on the relationship between marital status, family size, and the decision variables (employment and fertility). Russian women have a long history of strong attachment to the labor market. High participation rates prevail both among married and unmarried women. Moreover, mothers of one or two children are more likely to be employed than women without children. Only after the third birth does participation decline significantly. Predictably, the probability of a birth is always higher for married women (inclusive of cohabitation). The table shows that the birth counting process is non-linear. The birth hazard is highest for women without children. It then decreases monotonically for women with one and two children but picks up again for women with three and more children.

Women in rural areas have lower participation rates and higher birth rates (table 5). In particular, birth rates for high birth orders are much lower in cities.

Finally, table 6 shows the evolution of women's choices over their life- 
Table 3 - Descriptive Statistics

\begin{tabular}{|c|c|c|}
\hline & Mean & Std Dev \\
\hline \multicolumn{3}{|c|}{ Individuals (9,462 observations) } \\
\hline Years in sample & 3.5 & 2.5 \\
\hline Age in 1st period & 35.5 & 10.3 \\
\hline Experience in 1st period & 13.0 & 10.3 \\
\hline Less than Secondary Educ & $6.3 \%$ & \\
\hline Secondary Educ Complete & $17.0 \%$ & \\
\hline Vocational School Complete & $17.9 \%$ & \\
\hline Technical School Complete & $27.1 \%$ & \\
\hline University Degree or above & $31.7 \%$ & \\
\hline Urban Area & $78.2 \%$ & \\
\hline \multicolumn{3}{|c|}{ Person-year (32,934 observations) } \\
\hline Age & 37.6 & 9.7 \\
\hline Married & $67.7 \%$ & \\
\hline Birth & $3.78 \%$ & \\
\hline No Children & $18.1 \%$ & \\
\hline One Child & $40.8 \%$ & \\
\hline Two Children & $32.8 \%$ & \\
\hline Three Children & $6.6 \%$ & \\
\hline Four + Children & $1.7 \%$ & \\
\hline Employed & $74.2 \%$ & \\
\hline Experience & 14.4 & 10.0 \\
\hline Labor Income & $12,668.4$ & $10,943.9$ \\
\hline Other Income & $20,983.4$ & $34,948.6$ \\
\hline MC Eligible (2008-2011) & $52.4 \%$ & \\
\hline
\end{tabular}

Notes: Income variables are monthly amounts in 2011 rubles.

Table 4 - Employment and Births by Marital Status and Number of Children

\begin{tabular}{ccccccc}
\hline $\begin{array}{c}\text { \# of } \\
\text { children }\end{array}$ & \multicolumn{3}{c}{ Single/Not Cohab. } & \multicolumn{3}{c}{ Married/Cohab. } \\
& Empl. & \% birth & Obs & \% Empl. & \% birth & Obs \\
\hline 0 & 70.0 & 2.40 & 3,704 & 72.7 & 17.57 & 2,857 \\
1 & 80.5 & 1.16 & 4,209 & 76.1 & 4.95 & 9,147 \\
2 & 80.1 & 0.36 & 2,204 & 75.7 & 1.20 & 8,196 \\
3 & 66.6 & 0.99 & 404 & 58.4 & 1.31 & 1,675 \\
$4+$ & 48.6 & 1.83 & 109 & 36.7 & 3.97 & 428 \\
\hline Total & 75.9 & 1.43 & 10,630 & 73.4 & 4.90 & 22,304
\end{tabular}

Note: Number of children does not include recent born. 
Table 5 - Employment and Births: rural vs. urban

\begin{tabular}{ccccccc}
\hline $\begin{array}{c}\text { \# of } \\
\text { children }\end{array}$ & \multicolumn{3}{c}{ Rural Location } & \multicolumn{3}{c}{ Urban Location } \\
& \% Empl. & \% birth & Obs & \% Empl. & \% birth & Obs \\
\hline 0 & 56.6 & 8.39 & 1,288 & 74.7 & 9.16 & 5,273 \\
1 & 70.0 & 5.58 & 2,650 & 79.4 & 3.31 & 10,706 \\
2 & 68.2 & 1.09 & 3,034 & 80.1 & 0.99 & 7,366 \\
3 & 48.9 & 1.68 & 1,010 & 70.5 & 0.84 & 1,069 \\
$4+$ & 37.7 & 5.03 & 318 & 41.1 & 1.37 & 219 \\
\hline Total & 63.4 & 3.89 & 8,301 & 77.9 & 3.74 & 24,633 \\
\hline Note: Number of children does not include recent born.
\end{tabular}

cycle. Unsurprisingly, births are concentrated in the 20s and become less and less frequent after age 30. Employment rates follow a pattern that contrasts and complements the fertility cycle. Participation in the labor market starts at about $60 \%$ and increases during the $20 \mathrm{~s}$. The pick employment rate is reached only in the mid-30s and remains high until the late 40s. While our model restricts the planning horizon to the official retirement age at 55, a very significant fraction of Russian women work until much later in life.

\section{Estimation Results}

In this section we describe our parameter estimates and evaluate how well the model's predictions fit the sample data.

\subsection{Parameter Estimates}

Parameter estimates are presented in table 7 . Because the utility function is linear in consumption the coefficients have the natural metric of an annual (flow) amount in rubles of 2011.

The utility of work $\left(\alpha_{1}\right)$ is negative as expected and does not vary significantly across types. In addition, working implies giving up around $1.2 \%$ of consumption (this suggests consumption and leisure are complements). Note that working married women do not experience significantly lower utility $\left(\delta_{1}\right.$ is small)

The disutility of giving birth $\left(\alpha_{2}\right)$ is large in absolute value, while having children results in positive net benefits realized over the remaining lifetime $\left(\alpha_{3}-\alpha_{5}\right)$. In other words, having children involves large short-term losses that have to be balanced with long term gains. The parameters imply nonlinear net benefits in the number of children (e.g. having two children less than doubles utility). There are also important differences across types. In particular, type III individuals suffer lower losses with births and enjoy higher net benefits of having one or two children (but not three or more). 
Table 6 - Choice Distribution

\begin{tabular}{cccccc}
\hline Age & \multicolumn{2}{c}{ Non-employed } & \multicolumn{2}{c}{ Employed } & Total \\
Group & No Birth & Birth & No Birth & Birth & \\
\hline $22-24$ & 1,105 & 136 & 1,924 & 161 & 3,326 \\
& 33.22 & 4.09 & 57.85 & 4.84 & 100 \\
$25-27$ & 825 & 115 & 2,190 & 201 & 3,331 \\
& 24.77 & 3.45 & 65.75 & 6.03 & 100 \\
$28-30$ & 695 & 90 & 2,122 & 170 & 3,077 \\
& 22.59 & 2.92 & 68.96 & 5.52 & 100 \\
$31-33$ & 731 & 62 & 2,195 & 122 & 3,110 \\
& 23.5 & 1.99 & 70.58 & 3.92 & 100 \\
$34-36$ & 623 & 29 & 2,319 & 72 & 3,043 \\
& 20.47 & 0.95 & 76.21 & 2.37 & 100 \\
$37-39$ & 600 & 18 & 2,228 & 46 & 2,892 \\
& 20.75 & 0.62 & 77.04 & 1.59 & 100 \\
$40-44$ & 919 & 9 & 3,375 & 13 & 4,316 \\
& 21.29 & 0.21 & 78.2 & 0.3 & 100 \\
$45-49$ & 1,022 & 0 & 3,693 & 1 & 4,716 \\
& 21.67 & 0 & 78.31 & 0.02 & 100 \\
$50-54$ & 1,507 & 0 & 3,616 & 0 & 5,123 \\
& 29.42 & 0 & 70.58 & 0 & 100 \\
\hline Total & 8,027 & 459 & 23,662 & 786 & 32,934 \\
& 24.37 & 1.39 & 71.85 & 2.39 & 100 \\
\hline Note: Nunn
\end{tabular}

Note: Number of observations and percentages.

Married women face lower costs of giving birth while also enjoying relatively higher gains from having children $\left(\delta_{2}-\delta_{5}\right)$.

Consistent with the evidence on participation rates, the first two children decrease the disutility of work while three or more children increase it slightly. Small children decrease incentives to work $\left(\gamma_{6}-\gamma_{9}\right)$. Relative to secondary school dropouts, women with a degree suffer from disutility levels that increase with education attainment ${ }^{50}$. One possible explanation is that the value of leisure time is higher for highly educated women who tend to work more than others on average. For similar reasons labor market experience also increases the disutility of work.

At the beginning of their careers women enjoy wage growth of about $2.6 \%$ per year of work. The return to on the job experience peaks after 33.6 years, when it reaches $57.2 \%$ (these coefficients are similar to the OLS estimates is table A.5). In turn, a university degree increases expected earnings by $52.9 \%$ relative to secondary schooling. The model also captures earnings differentials across types (ceteris paribus type I baseline earnings are almost 3.5 times type III earnings). There are also significant differences in job offer probabilities ( $7.2 \%$ for type II, $39.3 \%$ for type I).

\footnotetext{
${ }^{50}$ Based on the estimates for the utility and the wage offer functions, the relative quality of vocational training appears to be below a regular secondary school degree.
} 
Table 7 - Maximum Likelihood Estimates

\begin{tabular}{|c|c|c|c|c|c|c|c|c|}
\hline \multicolumn{9}{|c|}{ Utility Function } \\
\hline Coeff. & Value & s.e. & Coeff. & Value & s.e. & Coeff. & Value & s.e. \\
\hline$\alpha_{1}($ type $=1)$ & $-5,088.25$ & 13.75 & $\beta_{1}$ & -0.0123 & $3.58 \mathrm{E}-05$ & $v_{2}$ & 387.44 & 1.29 \\
\hline$\alpha_{1}($ type $=2)$ & $-5,308.70$ & 15.16 & $\beta_{2}$ & -0.0523 & $1.39 \mathrm{E}-03$ & $\gamma_{1}$ & -179.79 & 3.22 \\
\hline$\alpha_{1}($ type $=3)$ & $-5,145.52$ & 87.26 & $\beta_{3}$ & $-5,538.97$ & 26.63 & $\gamma_{2}$ & -350.78 & 2.62 \\
\hline$\alpha_{2}($ type $=1)$ & $-111,417.27$ & $1,004.75$ & $\beta_{4}$ & -812.12 & 5.76 & $\gamma_{3}$ & -74.67 & 0.21 \\
\hline$\alpha_{2}($ type $=2)$ & $-112,366.83$ & $1,590.14$ & $\beta_{5}$ & -369.95 & 1.62 & $\gamma_{4}$ & $-1,042.54$ & 2.96 \\
\hline$\alpha_{2}($ type $=3)$ & $-100,588.22$ & $1,098.44$ & $\beta_{6}$ & $-2,835.03$ & 20.33 & $\gamma_{5}$ & $-7,199.09$ & 27.43 \\
\hline$\alpha_{3}($ type $=1)$ & $2,261.55$ & 15.90 & $\beta_{7}$ & $-1,423.59$ & 24.64 & $\gamma_{6}$ & $1,456.12$ & 43.19 \\
\hline$\alpha_{3}($ type $=2)$ & $2,388.87$ & 18.91 & $\beta_{8}$ & 1.7091 & 0.03 & $\gamma_{7}$ & 778.31 & 5.34 \\
\hline$\alpha_{3}($ type $=3)$ & $2,554.85$ & 13.63 & $\beta_{9}$ & $2,260.15$ & 9.93 & $\gamma_{8}$ & -434.12 & 2.45 \\
\hline$\alpha_{4}($ type $=1)$ & $3,962.68$ & 71.33 & $\beta_{10}$ & $-11,741.56$ & 205.68 & $\gamma_{9}$ & -955 & 17.49 \\
\hline$\alpha_{4}($ type $=2)$ & $4,224.11$ & 76.83 & $\beta_{11}$ & $-31,515.22$ & 802.48 & $\delta_{1}$ & -366.7 & 0.98 \\
\hline$\alpha_{4}($ type $=3)$ & $4,613.64$ & 45.22 & $\beta_{12}$ & $3,562.93$ & 19.53 & $\delta_{2}$ & $35,361.12$ & 288.49 \\
\hline$\alpha_{5}($ type $=1)$ & $5,182.21$ & 44.49 & $\beta_{13}$ & $1,215.18$ & 3.80 & $\delta_{3}$ & $1,573.64$ & 19.55 \\
\hline$\alpha_{5}($ type $=2)$ & $5,903.71$ & 139.13 & $v_{0}$ & 270.56 & 1.55 & $\delta_{4}$ & $1,356.88$ & 11.28 \\
\hline$\alpha_{5}($ type $=3)$ & $4,276.80$ & 27.26 & $v_{1}$ & $4,370.31$ & 26.72 & $\delta_{5}$ & 524.83 & 2.61 \\
\hline \multicolumn{9}{|c|}{ Labor Income } \\
\hline$a_{0}($ type $=1)$ & 11.5197 & $6.98 \mathrm{E}-03$ & $a_{1}$ & 0.0269 & $1.83 \mathrm{E}-04$ & $a_{4}$ & 0.0275 & $7.93 \mathrm{E}-04$ \\
\hline$a_{0}($ type $=2)$ & 10.881 & $3.76 \mathrm{E}-03$ & $a_{2}$ & -0.0004 & $3.72 \mathrm{E}-06$ & $a_{5}$ & 0.0984 & $1.86 \mathrm{E}-03$ \\
\hline$a_{0}($ type $=3)$ & 10.2741 & $4.75 \mathrm{E}-03$ & $a_{3}$ & 0.0654 & $3.14 \mathrm{E}-04$ & $a_{6}$ & 0.4898 & $5.99 \mathrm{E}-03$ \\
\hline \multirow{2}{*}{\multicolumn{6}{|c|}{ Job Offer Arrival }} & $a_{7}$ & 0.4177 & $4.58 \mathrm{E}-03$ \\
\hline & & & & & & \multicolumn{3}{|c|}{ Error Structure } \\
\hline$z_{0}($ type $=1)$ & -0.4365 & $1.74 \mathrm{E}-03$ & $z_{1}$ & 3.6636 & $1.72 \mathrm{E}-02$ & $\sigma_{y}$ & 0.4398 & $2.35 \mathrm{E}-03$ \\
\hline$z_{0}($ type $=2)$ & -2.5583 & $1.25 \mathrm{E}-02$ & $z_{2}$ & 0.3941 & $2.82 \mathrm{E}-03$ & $\sigma_{n}$ & $18,601.04$ & $6.22 \mathrm{E}+02$ \\
\hline$z_{0}($ type $=3)$ & -0.7775 & $5.03 \mathrm{E}-03$ & & & & $\rho_{n, y}$ & -0.7361 & $3.85 \mathrm{E}-02$ \\
\hline \multicolumn{6}{|c|}{ Type Proportions } & & & \\
\hline$\phi($ type $=1)$ & 0.0262 & $1.05 \mathrm{E}-04$ & $\kappa_{1}$ & 0.2527 & $4.30 \mathrm{E}-03$ & $\sigma_{u}$ & 0.0879 & \multirow[t]{3}{*}{$4.79 \mathrm{E}-04$} \\
\hline$\phi($ type $=2)$ & 0.0283 & $1.56 \mathrm{E}-04$ & $\kappa_{2}$ & 0.4923 & $4.45 \mathrm{E}-03$ & & & \\
\hline$\phi($ type $=3)$ & 0.0333 & $1.65 \mathrm{E}-04$ & $\kappa_{3}$ & 0.255 & $3.94 \mathrm{E}-03$ & $\log \mathrm{L}$ & $-31,574$ & \\
\hline
\end{tabular}

The $v$ parameters show that changes in the incentives to give birth post 2007 were negligible for non-working women. In contrast, the cost of giving birth for a single (married) employed woman was reduced by about $4 \%$ $(6 \%)$. The multipliers $(\phi)$ associated with MC policy range from $2.6 \%$ to $3.3 \%$ depending on the woman's type (the weighted average is $2.9 \%$ ). This implies that women apply some heavy discounting to the benefit amount $K{ }^{51}$ Specifically, the incentive to giving birth to or adopting a second or consecutive child is roughly equal to 10,600 rubles, or about ten percent of the disutility associated with a birth for a single woman.

In section seven, we use the estimated $\phi$ and $v$ parameters to calculate the long-run effect of the MC and other pro-natalist policies on fertility and labor force participation.

\subsection{Model Fit}

Figure 4 shows the ability of the model to reproduce the age profile for each of the four decisions. Figure 5 looks at participation and birth hazards separately. In general, the models seems to track the data well.

\footnotetext{
${ }^{51}$ In a similar exercise applied to U.S. data, Keane and Wolpin (2010) estimate a multiplier of $74.75 \%$ for welfare receipts. While there are restrictions in the use of welfare benefits (e.g., food stamps cannot be used to purchase tobacco products), these entitlements are much closer to cash than the MC benefit.
} 


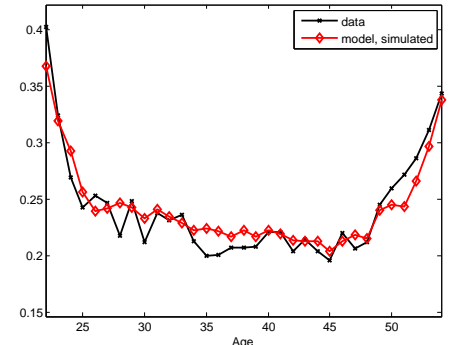

(a) No Work - No Child

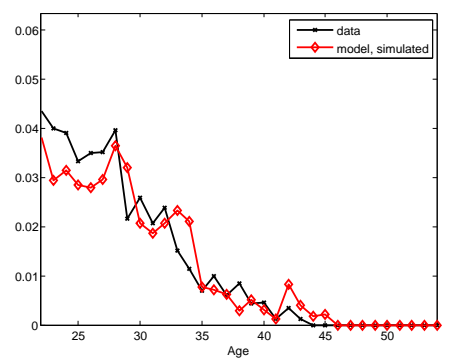

(c) No Work - Child

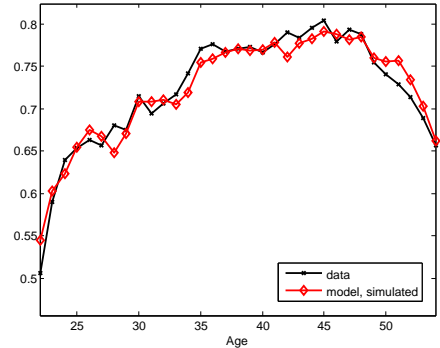

(b) Work - No Child

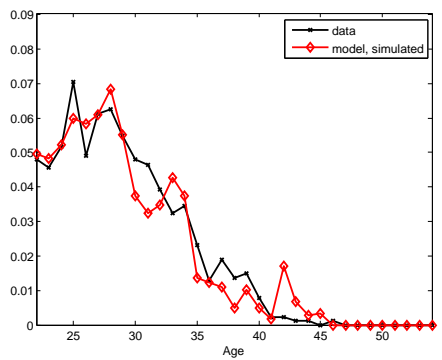

(d) Work - Child

Figure 4 - Model Fit for Mutually Exclusive Choices

Table 8 summarizes the model's ability to predict behavior. The table shows that the fit for the work decision is remarkably accurate, whereas the model underpredicts births very slightly. The model also tracks earnings quite well. Using the likelihood function to assign an unobservable type to each woman in the data, we are also able to look at the model's fit by type. Clearly, type I women specialize in work. They have the highest participation rates and earnings and the lowest birth rate. Type II women are second in the earnings ranking but - due to the low rate at which they receive job offers - have the lowest participation rates nonetheless. Type III women have the lowest earnings, the highest birth rates and are employed almost $90 \%$ of their lifetime. We estimate that type II is the most prevalent in Russia (49\%) while the rest of the population is roughly equally divided between the other two types. There are no significant differences in the ability of the model to predict the three types' behavior.

Table 9 shows transition probabilities among the mutually exclusive choices for women ages 22-45 and 46-54 and compares them to model predictions obtained from 100 simulations. The overall fit seems reasonable, although the model over-predicts transitions into the labor force for women in post-fertile age. 


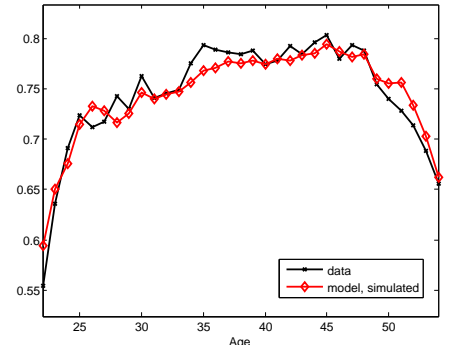

(a) LF Participation

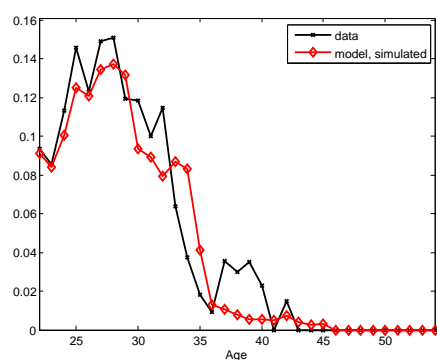

(c) First Births

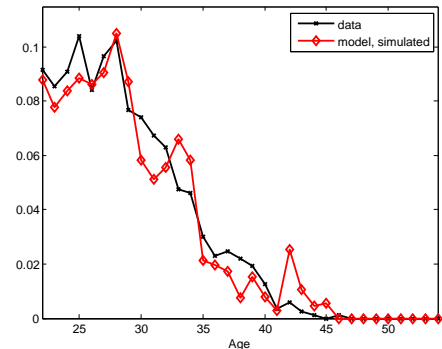

(b) Total Births

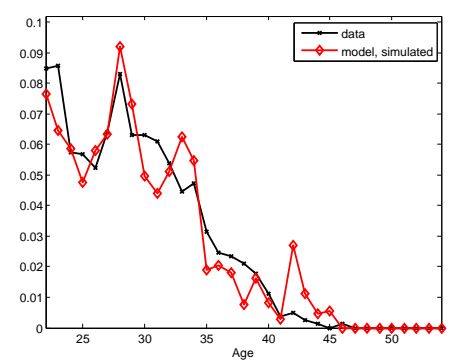

(d) Second+ Births

Figure 5 - Model Fit for LF Participation and Birth Hazards

Table 8 - Data versus Model

\begin{tabular}{ccccc}
\hline & All & Type I & Type II & Type III \\
\hline Labor Force & 0.7423 & 0.9312 & 0.5732 & 0.8858 \\
Participation & 0.7417 & 0.9309 & 0.5716 & 0.8865 \\
\hline Mean log & 11.93 & 12.48 & 11.81 & 11.27 \\
Annual Earnings & 11.84 & 12.38 & 11.74 & 11.16 \\
\hline Birth & 0.0519 & 0.0390 & 0.0525 & 0.0635 \\
Hazard & 0.0499 & 0.0364 & 0.0513 & 0.0608 \\
\hline Proportion (\%) & 100.0 & 25.3 & 49.2 & 25.5 \\
\hline
\end{tabular}

Note: White cells contain actual statistics. Gray cells contain model predictions based on 100 simulations. 
Table 9 - Transition Probabilities: data vs. model

\begin{tabular}{cccccccc}
\hline & \multicolumn{5}{c}{ Ages 22-45 } & & \multicolumn{2}{c}{ Ages 46-54 } \\
\cline { 2 - 4 } & $\begin{array}{c}\text { no birth } \\
\text { no work }\end{array}$ & $\begin{array}{c}\text { no birth } \\
\text { work }\end{array}$ & $\begin{array}{c}\text { birth } \\
\text { no work }\end{array}$ & $\begin{array}{c}\text { birth } \\
\text { work }\end{array}$ & $\begin{array}{c}\text { no birth } \\
\text { no work }\end{array}$ & $\begin{array}{c}\text { no birth } \\
\text { work }\end{array}$ \\
\hline no birth & 0.66 & 0.30 & 0.03 & 0.01 & & 0.78 & 0.22 \\
no work & 0.60 & 0.34 & 0.04 & 0.01 & & 0.69 & 0.31 \\
\hline no birth & 0.08 & 0.87 & 0.01 & 0.03 & & 0.09 & 0.91 \\
work & 0.11 & 0.85 & 0.01 & 0.04 & 0.11 & 0.89 \\
\hline birth & 0.68 & 0.24 & 0.08 & 0.01 & & \\
no work & 0.68 & 0.26 & 0.05 & 0.01 & & \\
\hline birth & 0.14 & 0.80 & 0.01 & 0.05 & & \\
work & 0.19 & 0.76 & 0.02 & 0.04 & & \\
\hline
\end{tabular}

Note: White cells contain actual transition probabilities. Gray cells contain model predictions based on 100 simulations. 


\section{Simulations}

Having estimated the parameters of the model, it is possible to compare the fertility behavior of women under different scenarios. In particular, we are interested in comparing behavior in a counterfactual in which the MC policy is not present. For this purpose, we simulate the lifetime decisions of a group of 22 year old women with the same initial characteristics as those found in our estimating sample. The simulation results are averages over 100 different draws from the joint distribution of the shocks.

Table 10 - Long-run Simulations

\begin{tabular}{lccc}
\hline & No & \multicolumn{2}{c}{ Differences } \\
& Policies & Total & MC Only \\
\hline Average \# of Children & 1.18 & +0.25 & +0.15 \\
& $(1.16,1.20)$ & $(0.22,0.27)$ & $(0.13,0.17)$ \\
Average Experience & 21.79 & -0.02 & +0.00 \\
& $(21.30,22.38)$ & $(-0.17,0.13)$ & $(-0.15,0.14)$ \\
\hline Family Size Distribution (\%) & & & \\
Childless & 22.4 & -4.9 & -2.2 \\
& $(21.4,23.4)$ & $(-6.2,-3.7)$ & $(-3.0,-1.5)$ \\
One Child & 44.2 & -8.9 & -7.3 \\
& $(43.8,44.8)$ & $(-11.3,-6.4)$ & $(-8.9,-5.6)$ \\
Two or more & 33.4 & +13.8 & +9.5 \\
& $(32.3,34.3)$ & $(11.2,16.0)$ & $(7.9,11.1)$ \\
\hline Note: Average model long run predictions (100 bootstraps) for a sample of 22 \\
year old women with the same characteristics as the estimating sample. In \\
parenthesis are 95\% confidence intervals.
\end{tabular}

The column labeled "no policies" in table 10 presents simulation results when the $v$ and $\phi$ parameters are set to zero. ${ }^{52}$ For women with the characteristics of current 22 year olds, the model predicts completed fertility of 1.18 children. ${ }^{53}$ When all parameters are set to their estimated values we find that total fertility increases by 0.25 children per woman. Note that the effect on work experience is statistically zero.

We also obtained simulations for the hypothetical case when the MC policy is in place but there are no other changes in the post-reform period ("MC Only" column in the table). The associated increase in total fertility of 0.15 children is our preferred estimate of the effect of the MC program in the long-run. Interestingly, this figure is very close to the differences in desired

\footnotetext{
${ }^{52}$ Strictly speaking, the $v$ parameters control for any changes in birth-related preferences post-2007 and not just maternity leave and child benefit policies.

${ }^{53}$ Among other factors, the relatively low predicted fertility responds to the higher education attainment of younger cohorts of women compared to the overall sample. While this is not the focus of this study, we consider this to be a worrying sign for future demographic evolution in Russia.
} 
number of children between women who claimed to have been influenced by $\mathrm{MC}$ and women that claimed not to have been influenced in the poll results (table 2). As expected, model-based estimates are significantly lower than the ones obtained from a BA or DID analysis.

While sixteen extra children per hundred women is a very modest effect, it is sufficient to induce a perceptible change in the typical family structure. According to the model simulations, the MC program is responsible for increasing the share of families with two or more children by almost 10 percentage points (see the lower panel of table 10).

\subsection{Short-run Simulations}

The short run response to the MC policy depends on the age of the woman at the time the reform is introduced. In order to obtain short run simulations we proceed as follows. First, as with the long run simulations, we take a group of 22 year old women with the same distribution of characteristics as in the sample. The simulated birth hazards for the pre-reform period are the weighted average, based on the age distribution of the sample, of the steady-state age-specific birth hazards when the reform-related parameters are set to zero.

Next, we obtain birth hazard paths for women shocked by the policies at different ages. We then use the birth hazards subsequent to the shock to compute weighted averages for the post-reform years. That is, the simulated hazard for the first year the policy is in place uses the first period response in fertility decisions, for the second year - the second period response and so on.

Figure 6 presents the simulation results. The overall birth hazard jumps almost two percentage points right after all policies are introduced. The effect withers away over time, with the birth rate converging to a new steady state of about $5.3 \%$. Most of this effect is due to the MC policy.

This simulation exercise confirms that much of the initial response to the MC policy corresponds to rescheduling of births rather than increases in long-run fertility. The short run predictions also show that, as expected, the MC policy had a relatively strong effect on second and consecutive births but almost no effect on first births. The non-zero effect on first births is explained by the higher option value of a second child when the policy is in place.

Note that these simulations are not meant to replicate observable birth rates as shown in figure 1. First, the simulations keep the age composition constant. Second, the initial characteristics used for simulation correspond to the subsample of 22 year-olds. For comparison purposes, we nevertheless 


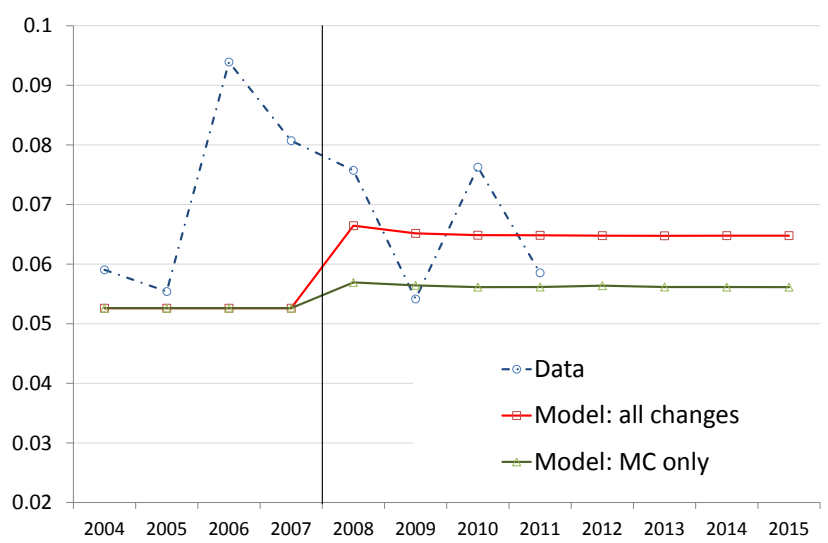

(a) First Births

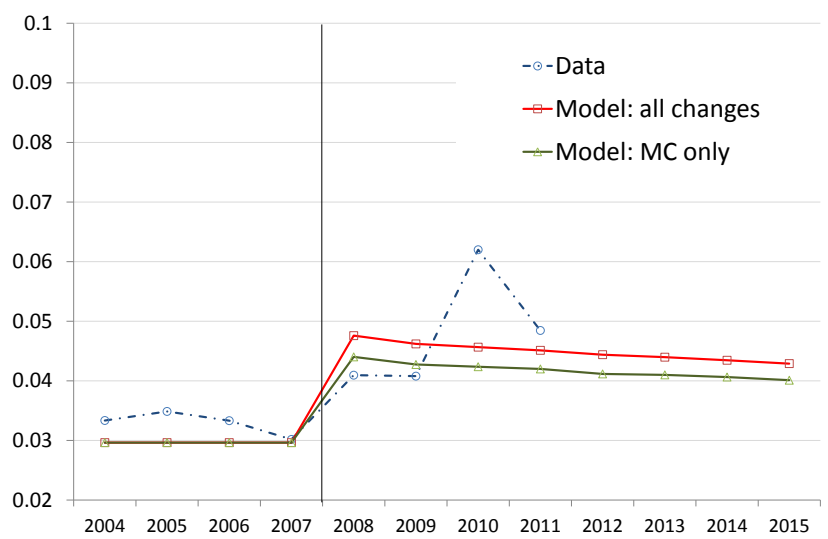

(b) Second+ Births

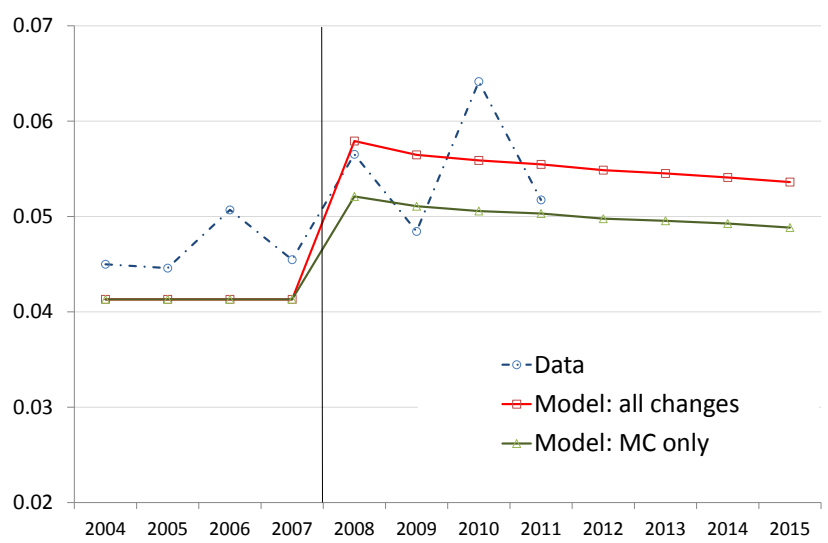

(c) All Births

Figure 6 - The Effect of the MC Program in Calendar Time 
include in the figures empirical age-composition-adjusted birth hazards. ${ }^{54}$

\subsection{Heterogeneous Effects}

Table 11 presents disaggregated long-run simulations by time-varying states (panel A), as well as for different subgroups (panel B).

Table 11 - Heterogenous Effects

\begin{tabular}{lccc}
\hline & \multicolumn{2}{c}{ No } & \multicolumn{2}{c}{ Differences } \\
& Policies & Total & MC Only \\
\hline Panel A & & & \\
Employed & 0.75 & +0.17 & +0.08 \\
Not Employed & 0.68 & +0.09 & +0.08 \\
& & & \\
Married & 1.06 & +0.21 & +0.12 \\
Single & 0.36 & +0.05 & +0.03 \\
\hline Panel B & & & \\
University Degree & 1.01 & +0.23 & +0.11 \\
No Degree & 1.24 & +0.28 & +0.17 \\
& & & \\
Urban & 1.11 & +0.27 & +0.15 \\
Rural & 1.41 & +0.24 & +0.16 \\
& & & \\
Type I & 0.96 & +0.24 & +0.10 \\
Type II & 1.21 & +0.27 & +0.18 \\
Type III & 1.43 & +0.28 & +0.17 \\
\hline $\begin{array}{l}\text { Notes: Panel A disaggregates } \\
\text { fertility into time-varying states. Panel B presents } \\
\text { simulated fertility for different subgroups. }\end{array}$
\end{tabular}

Women are predicted to have slightly more children while employed than non-employed. In turn, while the overall effect of the post-2007 changes is stronger for employed women the MC policy effect is the same in both labor market states. This result corresponds to our finding of a significant shift in the disutility of pregnancy for employed women in the post-reform period $\left(v_{1}\right)$. A key advantage of these model-based predictions is that they are selection-adjusted; i.e. they consider the joint-effect of the policies on labor supply and fertility.

As explained above, some of the increases in maternity benefits post-2007 were larger for second and consecutive order births than for first borns. These changes were specially important for non-employed women (only a small minority of employed women have earnings low enough to be affected). Since the model cannot separately identify the effect of these changes from

\footnotetext{
${ }^{54}$ The adjusted birth hazards are a weighted average of age-specific birth rates for women of fertile age, where the weights are fixed according to the overall age distribution in the sample.
} 
those of the MC policy, the selection-adjusted estimates of the effect on fertility across employment status provide an important robustness check. Had these birth-order-specific changes been an important confounding factor, we would expect the estimated MC effect to be larger among the non-employed. The fact that this is not the case is reassuring that our estimate of the MC effect is unbiased.

As is intuitive, married or cohabiting women are predicted to have more children than singles. We also find that the policy response for married women is much larger than for single women. In this case, the result has to do with the size of the policy incentive relative to the disutility of births, which is substantially higher for the latter. Consequently, in this case the differential response is observed both for MC and the other post-2007 changes.

The results in panel $\mathrm{B}$ show that the policies had relatively stronger effects on women without a college degree. We also find that the response to the MC policy is inversely related to unobservable types' potential earnings. Overall, the MC program seems to have more strongly affected relatively underprivileged women (however, we find essentially no difference between rural and urban locations).

\section{Conclusion}

The total fertility rate in Russia declined sharply during the 1990s and has remained below replacement level for over two decades. This development has raised concerns as the long-run effects of population decline could be devastating for the social security system and might have other dreadful consequences in an already sparsely populated country. As a response, the government has recurred to direct monetary incentives. Starting in 2007, the MC program provides women who give birth to or adopt a second or consecutive child benefits worth about $\$ 11,000$.

In addition to the sheer magnitude of the committed resources, assessing the effectiveness of the MC policy is important because other countries facing a demographic crisis might consider following a similar strategy. Unfortunately, the evaluation of the program is complicated by several methodological issues. First, there is the classic issue of confounding factors. In particular, maternity leave and child benefits were improved around the same time the MC program was started. Second, it will be decades before the cohorts affected by the policy complete their fertile period.

In order to overcome these challenges, in this paper we estimate a structural model of fertility and labor force participation. The model allows us to obtain an estimate of the long-run effect of the MC program on fertility that is less prone to upward bias due to confounding factors or rescheduling of births. We find that the policy increases fertility by about 0.15 children 
per woman and leads to an increase of almost 12 percentage points in the share of households with two or more children. Simulation results suggest that much of the increase in birth rates post-2007 is due to rescheduling of births and not long-run increases in fertility. We also find that the policy did not have differential effects by employment status but that there was a stronger response by women with a spouse in the household. Finally, there is some evidence that relatively underprivileged women were more affected by the policy, although we find no significant differences between urban and rural areas.

The simulation-based results are subject to the caveat that estimating a structural model requires making many functional form and distributional assumptions. In particular, in order to avoid modelling schooling and marriage decisions - which would make the model computationally infeasiblewe have opted for restricting the exercise to women of at least 22 years of age and to assume that marriage and divorce occur following an exogenous process. To the extent possible, we have tried to justify these and other assumptions by reference to empirical data and/or to previous work. In some cases, we have estimated alternative versions of the model as a robustness check. Finally, the model allows for unobservable heterogeneity in several key parameters. It is certainly less restrictive to specify a model that approximates a distribution of costs and benefits of having children than assuming a fixed set of parameters exists that captures these costs.

However, some assumptions are difficult to verify and some uncertainty (over and above that reflected in standard errors) necessarily remains. Partly for this reason, we have opted for presenting a range of diverse evidence, including administrative time-series, BA and DID estimates (both regressionbased and nearest neighbour matching), and poll results. With the exception of the latter, this descriptive evidence points toward a significantly higher effect of the MC policy (about 0.4 children per woman). Our interpretation is that these estimates are strongly upward biased. In particular, previous studies suggest that pro-natalist policies lead to rescheduling of births. The BA and DID estimates are also bound to pick the effect of the improvement in maternity leave and child benefits. Finally, the poll data suggest very modest effects of the MC program, a result more in line with the modelbased estimates than the BA or DID experiments.

In summary, the main contribution of the current study consists in showing that the effectiveness of the MC program is much lower than what a simple descriptive analysis would suggest. Is MC a good policy? A formal answer would require a welfare analysis. In particular, it would be necessary to make assumptions regarding the alternative use of the resources destined to the program. Such analysis will be left for future research. 


\section{References}

Arroyo, C. and Zhang, J. Dynamic Microeconomic Models of Fertility Choice: A survey. Journal of Population Economics, 10(1):23-65, 1997.

Becker, G. Grappling with Russia's Demographic Time Bomb. The BeckerPosner Blog, 2006. http://www.becker-posner-blog.com.

Becker, G. S. An Economic Analysis of Fertility. In Demographic and Economic Change in Developed Countries, Universities-National Bureau of Economic Research Conference Series 11, pages 209-231. NBER, Princeton, NJ, 1960.

Bertrand, M.; Duflo, E., and Mullainathan, S. How Much Should We Trust Differences-in-Differences Estimates? Quarterly Journal of Economics, 119(1):249-275, 2004.

Brainerd, E. The Demographic Transformation of Post-Socialist Countries: Causes, Consequences, and Questions. In Roland, G., editor, Economies in Transition: The Long-Run View, pages 57-83. Palgrave Macmillan, 2012 .

Chen, D. Can Countries Reverse Fertility Decline? Evidence from Frances Marriage and Baby Bonuses, 1929-1981. International Tax and Public Finance, 18(3):253-272, 2011.

Denisova, I. and Shapiro, J. Recent Demographic Developments in the Russian Federation. In Alexeev, M. and Weber, S., editors, The Oxford Handbook of the Russian Economy, chapter 33, pages 800-826. Oxford University Press, 2013.

Dickert-Conlin, S. and Chandra, A. Taxes and the Timing of Births. Journal of Political Economy, 107(1):161-177, 1999.

Francesconi, M. A Joint Dynamic Model of Fertility and Work of Married Women. Journal of Labor Economics, 20(2):336-380, 2002.

Gans, J. and Leigh, A. Born on the First of July: An (un) Natural Experiment in Birth Timing. Journal of Public Economics, 93(1-2):246-263, 2009 .

Hotz, J. V.; Klerman, J., and Willis, R. The Economics of Fertility in Developed Countries. In Rosenzweig, M. R. and Stark, O., editors, Handbook of Population and Family Economics, volume IA, pages 275-347. Elsevier Science, 1997.

Hotz, V. J. and Miller, R. A. An Empirical Analysis of Life Cycle Fertility and Female Labor Supply. Econometrica, 56(1):91-118, 1988. 
Keane, M. and Wolpin, K. Exploring The Usefulness Of A Nonrandom Holdout Sample For Model Validation: Welfare Effects On Female Behavior. International Economic Review, 48(4):1351-1378, 2007.

Keane, M. and Wolpin, K. The Role Of Labor And Marriage Markets, Preference Heterogeneity, And The Welfare System In The Life Cycle Decisions Of Black, Hispanic, And White Women. International Economic Review, 51(3):851-892, 2010.

McFadden, D. A Method Of Simulated Moments For Estimation Of Discrete Response Models Without Numerical Integration. Econometrica, 57(5): 995-1026, Sep 1989.

Milligan, K. Subsidizing the Stork: New evidence on Tax Incentives and Fertility. Review of Economics and Statistics, 87(3):539-555, 2005.

Smith, J. and Todd, P. Does Matching Overcome LaLonde's Critique of Nonexperimental Estimators? Journal of Econometrics, 125(1):305-353, 2005 .

Wolpin, K. An Estimable Dynamic Stochastic Model of Fertility and Child Mortality. The Journal of Political Economy, 92:852-874, 1984.

Zakharov, S. Increases in Fertility in 2007-2010: Cause for Optimism? Demoscope Weekly, pages 495-496, Jan 23-Feb 5 2012. In Russian, http://demoscope.ru/weekly/2012/0495/tema01.php. 


\section{A Appendix: additional figures and tables}

Figure A.1 - Birth Rates and TFR since 1959

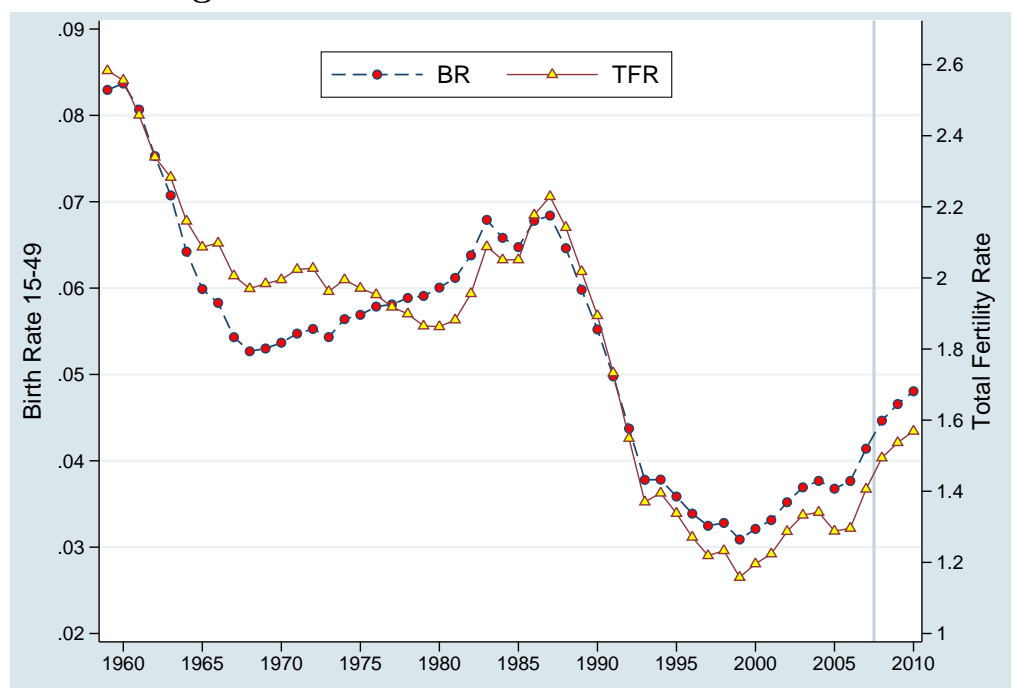

Notes: The data source is the Human Fertility Database. For the period 1994-2010, it coincides with the Rosstat-HFD series in figures 1 and 2.

Figure A.2 - Birth Rates By Birth Order for Women Ages 15-39

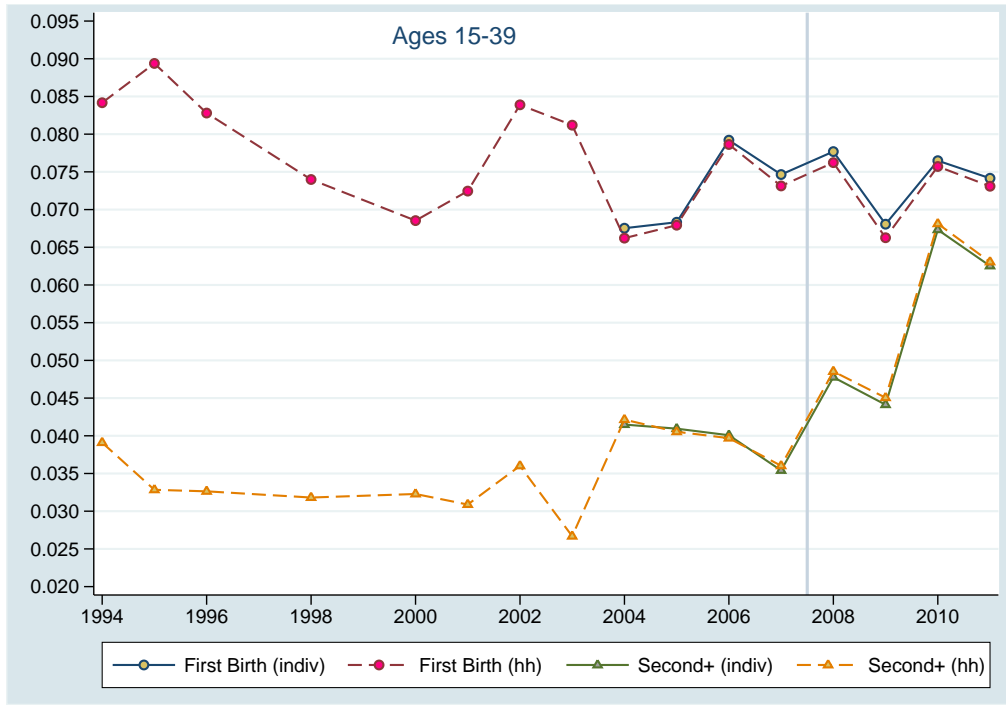

Notes: The data source is the RLMS. See notes to figure 3. 


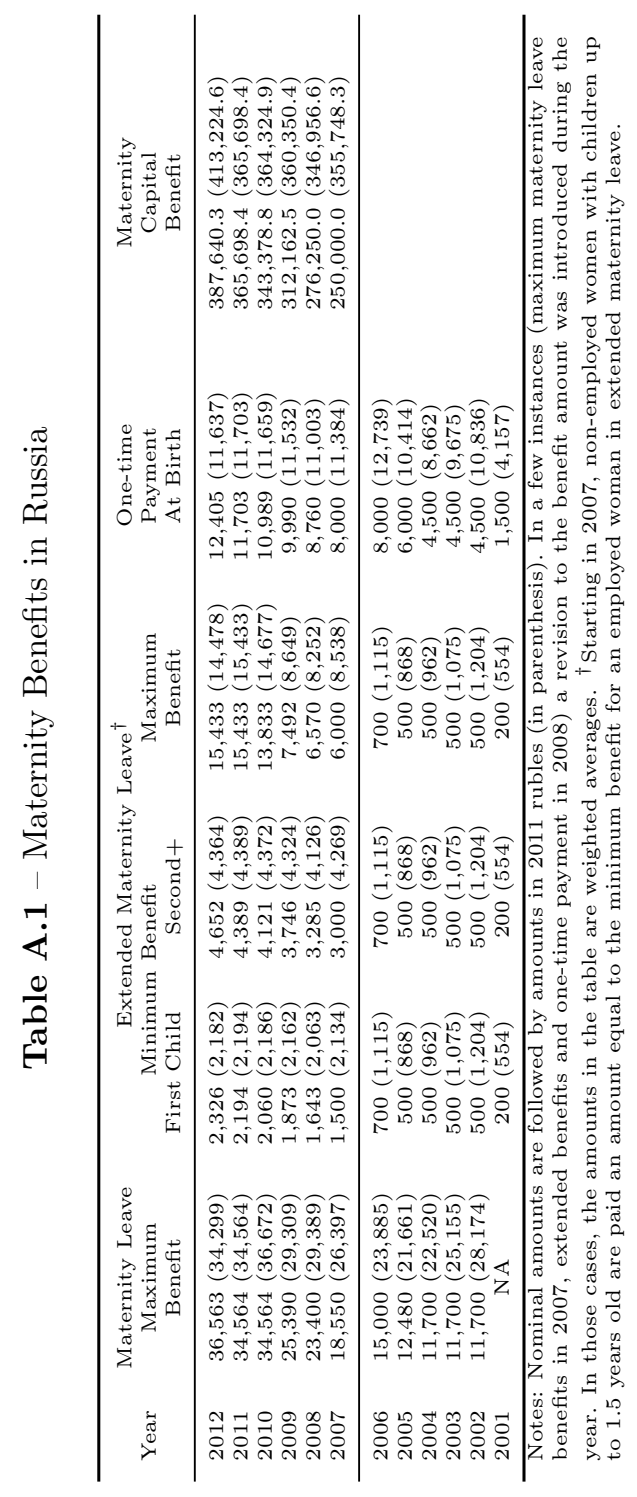


Table A.2 - Additional Results for Poll on MC Policy

\begin{tabular}{|c|c|c|}
\hline A. Information and Beliefs about MC & Males & Females \\
\hline Knows "something" about MC & $\begin{array}{c}47.7 \% \\
(4,823)\end{array}$ & $\begin{array}{r}64.8 \% \\
(6,693)\end{array}$ \\
\hline $\begin{array}{l}\text { Gives correct answer to: } \\
\ldots \text { amount of MC benefit }\end{array}$ & $\begin{array}{c}93.9 \% \\
(2,185)\end{array}$ & $\begin{array}{c}94.9 \% \\
(4,128)\end{array}$ \\
\hline ... eligibility rule & $\begin{array}{c}91.5 \% \\
(2,168)\end{array}$ & $\begin{array}{c}93.3 \% \\
(4,180)\end{array}$ \\
\hline$\ldots$ waiting time to receive benefit & $\begin{array}{l}87.8 \% \\
(2,001)\end{array}$ & $\begin{array}{l}90.3 \% \\
(3,954)\end{array}$ \\
\hline$\ldots$ whether $\mathrm{MC}$ can be received in cash & $\begin{array}{l}90.1 \% \\
(1,971)\end{array}$ & $\begin{array}{l}91.2 \% \\
(3,836)\end{array}$ \\
\hline $\begin{array}{l}\text {... whether MC benefits can be split into } \\
\text { separate uses }\end{array}$ & $\begin{array}{c}37.9 \% \\
(1,822)\end{array}$ & $\begin{array}{r}36.8 \% \\
(3,504)\end{array}$ \\
\hline $\begin{array}{l}\text { Has drawn up MC certificate } \\
\text { (eligible women only) }\end{array}$ & - & $\begin{array}{c}50.8 \% \\
(134)\end{array}$ \\
\hline $\begin{array}{l}\text { Believes eligible women will be able to get } \\
\text { the money from government }\end{array}$ & $\begin{array}{c}66.7 \% \\
(1,914) \\
\end{array}$ & $\begin{array}{r}67.6 \% \\
(3,598) \\
\end{array}$ \\
\hline B. Benefit Use & Males & Females \\
\hline $\begin{array}{l}\text { Planning to spend } \mathrm{MC} \text { benefits in } \\
\ldots \text {. improvement of family's living conditions }\end{array}$ & $\begin{array}{c}47.6 \% \\
(1,992)\end{array}$ & $\begin{array}{c}46.4 \% \\
(3,842)\end{array}$ \\
\hline ... children's education & $\begin{array}{l}48.4 \% \\
(1,992)\end{array}$ & $\begin{array}{l}49.4 \% \\
(3,842)\end{array}$ \\
\hline ... cumulative part of mother's pension & $\begin{array}{c}4.0 \% \\
(1,992)\end{array}$ & $\begin{array}{c}4.2 \% \\
(3,842)\end{array}$ \\
\hline $\begin{array}{l}\text { Subsample of eligible women: } \\
\ldots \text { improvement of family's living conditions }\end{array}$ & - & $\begin{array}{c}62.7 \% \\
(324)\end{array}$ \\
\hline ... children's education & - & $\begin{array}{l}34.3 \% \\
(324)\end{array}$ \\
\hline ...cumulative part of mother's pension & - & $\begin{array}{l}3.1 \% \\
(324)\end{array}$ \\
\hline
\end{tabular}


Table A.3 - Full Regression Results

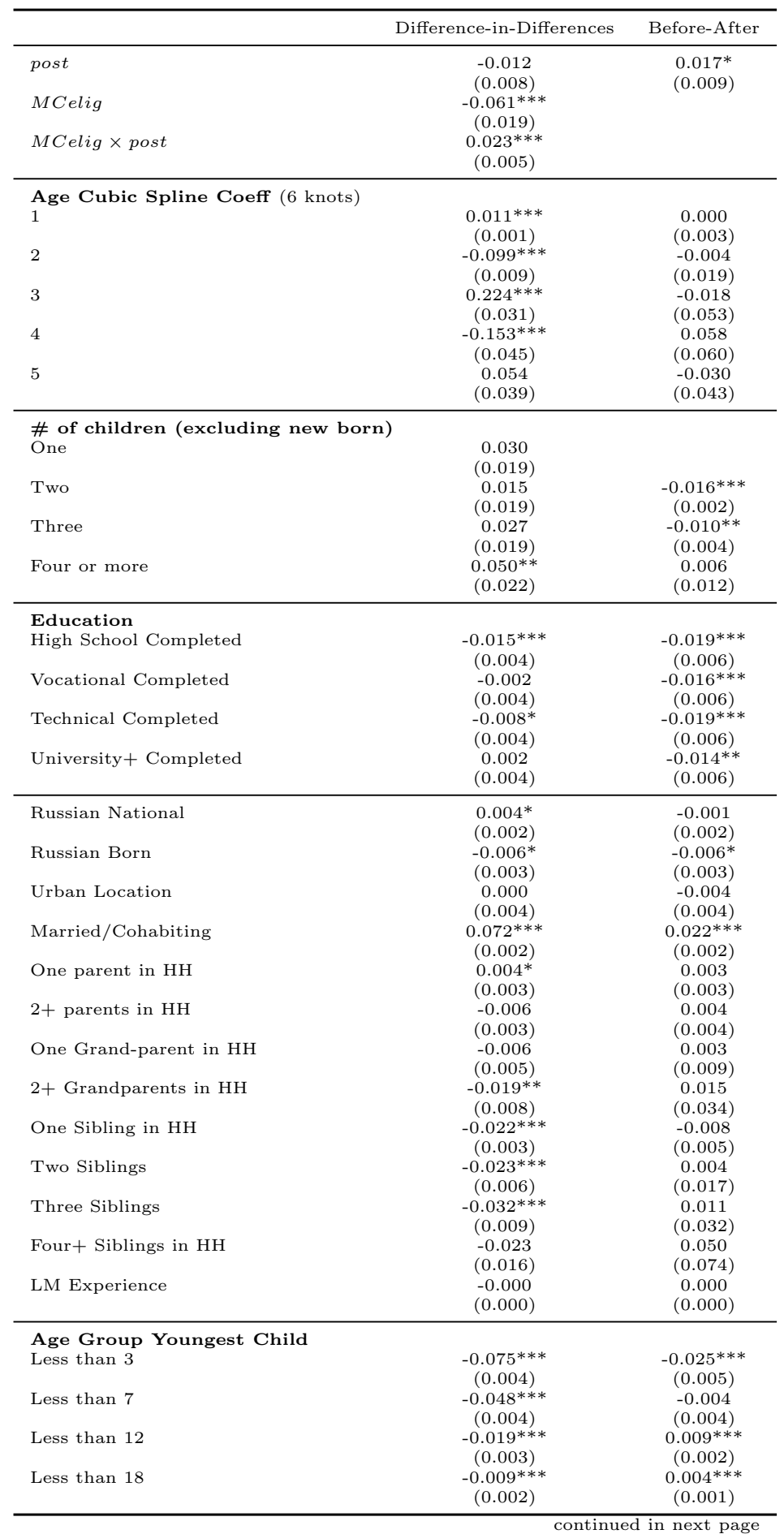


continued from previous page

\begin{tabular}{lcc}
\hline Child Care & & \\
State Nursery & $-0.012^{* * *}$ & $-0.014^{* * *}$ \\
Private Nursery & $(0.003)$ & $(0.003)$ \\
& $-0.007^{* *}$ & -0.004 \\
State Preschool & $(0.004)$ & $(0.004)$ \\
& $-0.010^{* *}$ & -0.006 \\
Private Preschool & $(0.005)$ & $(0.005)$ \\
& $0.007^{*}$ & 0.003 \\
Median Amount Paid for Childcare & $(0.004)$ & $(0.004)$ \\
& -0.000 & 0.001 \\
Proportion with Free Care & $(0.001)$ & $(0.001)$ \\
& 0.012 & 0.007 \\
& $(0.020)$ & $(0.022)$ \\
\hline \hline Observations & 53,463 & 32,746 \\
R-squared & 0.076 & 0.036 \\
\hline Notes: Robust s.e. clustered at individual level. The cubic spline knots are $20,25, \ldots$,
\end{tabular}

Notes: Robust s.e. clustered at individual level. The cubic spline knots are 20,
45. Education baseline is no degree. Year, location, and the constant are omitted. 
Table A.4 - Evolution of Marital Status

\begin{tabular}{ccc}
\hline Age & \multicolumn{2}{c}{ Transition } \\
Group & $\operatorname{Pr}\left(m_{t}=1 \mid m_{t-1}=0\right)$ & $\operatorname{Pr}\left(m_{t}=0 \mid m_{t-1}=1\right)$ \\
\hline $22-25$ & 11.62 & 5.1 \\
$26-30$ & 15.64 & 4.67 \\
$31-35$ & 11.04 & 3.34 \\
$36-40$ & 7.46 & 3.39 \\
$41-45$ & 5.52 & 2.75 \\
$46-50$ & 3.86 & 3.07 \\
$51-55$ & 2.51 & 2.9 \\
\hline
\end{tabular}

Table A.5 - Non-labor Income, Labor Income and Employment Probability

\begin{tabular}{|c|c|c|c|}
\hline & $\begin{array}{l}\text { Eq. (7) } \\
\log y_{t}^{o}\end{array}$ & $\begin{array}{c}\text { Eq. (9) } \\
\log y_{t}^{f}\end{array}$ & $\begin{array}{c}\text { Eq. }(8) \\
\operatorname{logit}\left(l_{t}\right)\end{array}$ \\
\hline$m_{t}$ & $\begin{array}{c}0.9494^{* * *} \\
(0.0115)\end{array}$ & & \\
\hline$t$ & $\begin{array}{c}-0.0232^{* * *} \\
(0.0049)\end{array}$ & & \\
\hline$t^{2}$ & $\begin{array}{c}0.0003^{* * *} \\
(0.0001)\end{array}$ & & \\
\hline$S_{1}$ & $\begin{array}{c}0.1300^{* * *} * \\
(0.0247)\end{array}$ & $\begin{array}{c}0.0855^{* * *} * \\
(0.0259)\end{array}$ & \\
\hline$S_{2}$ & $\begin{array}{c}0.0509^{* *} \\
(0.0242)\end{array}$ & $\begin{array}{c}0.0309 \\
(0.0249)\end{array}$ & \\
\hline$S_{3}$ & $\begin{array}{c}0.1025^{* * *} \\
(0.0234)\end{array}$ & $\begin{array}{c}0.1260^{* * *} \\
(0.0241)\end{array}$ & \\
\hline$S_{4}$ & $\begin{array}{c}0.3437^{* * *} * \\
(0.0233)\end{array}$ & $\begin{array}{c}0.5158^{* * *} * \\
(0.0238)\end{array}$ & \\
\hline$G$ & $\begin{array}{c}0.3710^{* * *} \\
(0.0123)\end{array}$ & $\begin{array}{c}0.3928^{* * *} * \\
(0.0115)\end{array}$ & $\begin{array}{c}0.3758 * * * \\
(0.0380)\end{array}$ \\
\hline$X_{t-1}$ & & $\begin{array}{c}0.0208^{* * *} \\
(0.0019)\end{array}$ & \\
\hline$X_{t-1}^{2}$ & & $\begin{array}{c}-0.0004^{* * *} \\
(0.0001)\end{array}$ & \\
\hline$l_{t-1}$ & & & $\begin{array}{c}3.6969^{* * *} \\
(0.0380)\end{array}$ \\
\hline Constant & $\begin{array}{c}11.3009 * * * \\
(0.0905)\end{array}$ & $\begin{array}{c}10.9209^{* * *} * \\
(0.026)\end{array}$ & $\begin{array}{c}-1.8312^{* * * *} \\
(0.0411)\end{array}$ \\
\hline Observations & 30,367 & 24,445 & 32,934 \\
\hline $\mathrm{R}$-squared & 0.2152 & 0.1368 & \\
\hline
\end{tabular}

